\title{
Variabilidad y función de la cerámica del sitio Wari de Marayniyoq, Ayacucho, Perú
}

\author{
Lidio M. Valdez*
}

Resumen En este artículo se discute la función de las vasijas de cerámica recuperadas mediante excavaciones arqueológicas del sitio Wari de Marayniyoq, ubicado en el valle de Ayacucho. Para su efecto, se emplea la evidencia etnográfica como un instrumento que permita definir la función de las piezas. De este análisis se desprende que una gran mayoría de las vasijas encontradas en Marayniyoq fueron originalmente manufacturadas para almacenar y transportar bebidas. Una vez rajadas o fragmentadas, muchas de estas vasijas fueron restauradas para ser re-utilizadas. Esta vez, las vasijas parecen haber sido utilizadas para almacenar granos. Por cuanto hay otras evidencias arqueológicas sugieren que Marayniyoq fue un centro de procesamiento de granos, dichas vasijas restauradas parecen haber cumplido la función de graneros. Dicho grano probablemente fue el maíz procesado conocido como qora, mientras que las vasijas originalmente, muy probablemente sirvieron para procesar, fermentar y transportar la chicha. Por cuanto la producción de la chicha en tiempos Inka fue asociado con la actividad de la mujer, algunos datos vienen también sugiriendo que durante el auge de Wari la chicha fue también por la mujer.

Palabras clave Andes Centrales, Wari, batanes, vasijas, qora, chicha, mujer

Abstract In this paper I discuss the function of the pottery assemblage uncovered from the Wari site of Marayniyoq, in the Ayacucho Valley, of the central highlands of Peru. Using the ethnographic example as a model to define the function of pottery vessels, this study indicates that the large pottery vessels found at Marayniyoq were originally manufactured to store and transport beverages. Once broken, most of these large vessels were restored and reused. At this stage, the vessels were no longer used for the original purpose, but instead as storage vessels. Because at the site there is grinding equipment that suggests that grinding was also an important activity, it is apparent that the restores vessel were used to store grains that perhaps were used in fermented beverages such as chicha. Consequently, at Marayniyoq we have a clear evidence for the reuse of large pottery vessels. Because during Inka times fermented maize beer was produced by women, there is also some evidence that suggests that something similar also existed during the time of the development of Wari.

Keywords Central Andes, Wari, grinding stones, vessels, maize beer production, women

* Department of Anthropology and Indigenous Studies, University of Victoria, Canadá. Correo electrónico:lvaldez@uvic.ca 
"La demanda de ciertas formas de cerámica está siempre asociada a los valores económicos de una comunidad. Entre la población Quechua de los Andes peruanos, por ejemplo, la mayoría del repertorio de vasijas utilitarias están asociadas con la agricultura del maíz. Vasijas de cerámica son utilizados por lo general para cocinar y transportar agua, pero un mayor número de formas

utilitarias son para cocinar y preparar el maíz que cualquier otro producto" (Arnold 1985:150).

La reconstrucción de antiguas actividades humanas depende del análisis funcional de los varios elementos culturales hallados en contextos definidos y recuperados mediante excavaciones sistemáticas. Tal como David Clarke anotó en su oportunidad, la consideración tanto del espacio físico como de los mismos artefactos hallados en asociación son de vital importancia para definir y comprender el rol de un determinado sitio arqueológico (Clarke 1977:9). En este caso, la función de dichos artefactos determina la función del espacio físico. Por ejemplo, la presencia de instrumentos asociadas con la producción de cerámica en un determinado espacio físico servirá para definir que dicho espacio, o el sitio en general, fue destinado a la producción de la cerámica. Éste es el caso específico de Conchopata (ver Pozzi-Escot 1985, 1991). Por consiguiente, la definición de la función de los diversos componentes de un espacio físico es de mucha importancia para tal interpretación.

La interrogante que surge de inmediato es, desde luego, cómo los especialistas definimos la función de los artefactos. En otras palabras, qué variables y elementos de juicio tomamos en cuenta para definir que una clase de artefactos fueron asociados, por ejemplo, con la producción de la cerámica. Tal como David y Kramer (2001:1-2) sostienen, la función de los artefactos, y por consiguiente de su asociado espacio físico, está basado en la inferencia analógica (Lumbreras 1984:3). En efecto, los especialistas determinamos la "fun- ción" de acuerdo a nuestra experiencia y percepción; esto quiere decir, que si en la actualidad un tipo de artefacto cumple una determinada función, se asume que dicho artefacto cumplió una función similar en el pasado. Como tal, toda reconstrucción arqueológica está fuertemente acondicionada por el empleo de la analogía.

Considerando que todo espacio físico cumple funciones determinadas, los especialistas acostumbramos definir, por ejemplo, "áreas de actividad" (Flannery \& Winter 1976:34), o simplemente a distinguir entre estructuras domésticas y públicas, zonas de habitación y zonas de enterramiento, lugares de almacenamiento y talleres. Un ejemplo concreto es el caso del sitio Inka de Huánuco Pampa que precisamente disponía de una diversidad de áreas orientadas a cumplir funciones específicas (ver Morris \& Thompson 1985). Dicha definición, tal como se puede anticipar, está basada en la presencia de determinados tipos de artefactos que una vez más permiten a los especialistas inferir una determinada función mediante la analogía. Como tal, definida la función de los artefactos, se puede también inferir la función de ambientes determinados o en su efecto de sitios completos. Nuevamente, dicha definición depende grandemente de la inferencia analógica. Por lo tanto, queda poca duda que toda interpretación arqueológica está basada en la analogía, definida precisamente como "una forma de inferencia" (David \& Kramer 2001:1).

Al mismo tiempo, es preciso anotar que la función de los artefactos es culturalmente definida. Esto quiere decir, por ejemplo, que no obstante vasijas de cerámica son manufacturadas por lo general para almacenar determinados productos, cocinar y transportar comidas y bebidas (Arthur 2002:332), la función de las vasijas utilitarias en particular es localmente acondicionada por el tipo de actividad sobre la cual gira la economía de una determinada comunidad (Arnold 1985:105). Estas son algunas de las observaciones que se deben tener en cuenta toda vez que se reconstruye la función de estructuras, artefactos, o en su efecto de sitios completos. 


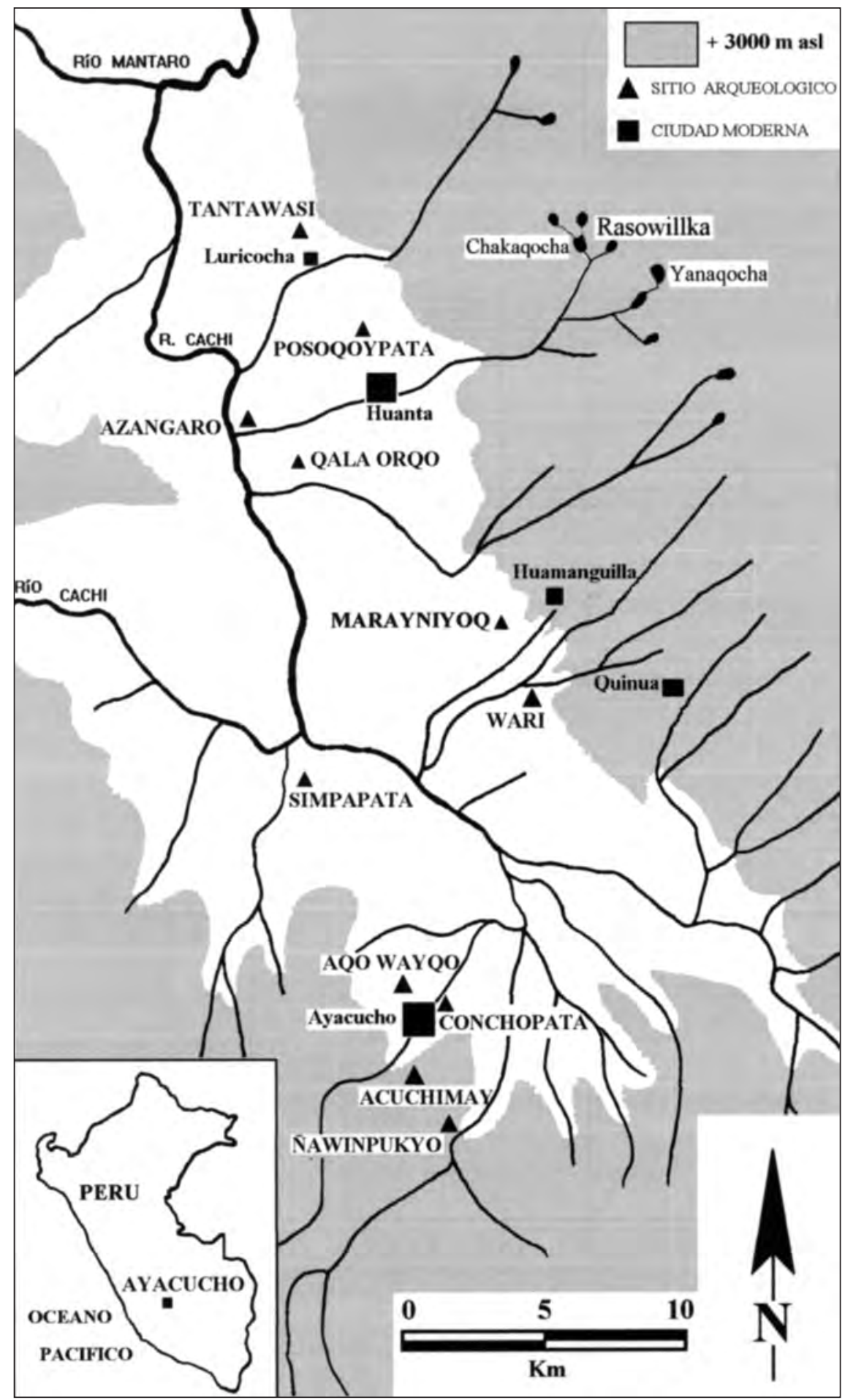

Figura 1. Ubicación del sitio de Marayniyoq en el valle de Ayacucho. 
Teniendo como punto de partida lo anteriormente señalado, la intención de este trabajo es definir y discutir la función de las vasijas de cerámica provenientes de Marayniyoq, un sitio Wari ubicado en el valle de Ayacucho (Figura 1), en la sierra central del Perú (Valdez 2002a; Valdez, Bettcher \& Valdez 2002; Valdez, et al., 2001). Dicha definición servirá para la interpretación de la función de espacios específicos del sitio en mención. La evaluación de componentes adicionales hallados en el mismo contexto servirá, por último, en la interpretación del papel de Marayniyoq. Para tal propósito, primero se define la forma de las vasijas teniendo como punto de referencia la evidencia etnográfica local (Arnold 1993; Valdez 1997). En seguida, se hace una breve referencia a las excavaciones efectuadas en Marayniyoq, sobre todo a la proveniencia de las piezas de cerámica. Luego se define las formas de vasijas de cerámica de Marayniyoq, siempre teniendo como referencia a la evidencia etnográfica local. En base a dicha definición se discute la función tanto de la colección de cerámica de Marayniyoq, como de los ambientes de donde provienen dichas colecciones. Por último, los datos aquí presentados sirven para evaluar el rol del sitio en general; para su efecto, se discute brevemente la función de artefactos adicionales hallados en los mismos contextos que las vasijas de cerámica. Ésta se complementa con los fechados de carbón obtenidos para Marayniyoq.

\section{Forma y función de la cerámica}

La mejor y más precisa manera de definir la forma de las vasijas de cerámica es contando con ejemplares completos. Sin embargo, muestras completas de vasijas ocurren solo ocasionalmente en sitios como Marayniyoq, de tal modo que los especialistas no tenemos ese privilegio de trabajar con muestras íntegras. No habiendo otra alternativa, a menudo se reconstruye la forma de las vasijas a partir de los fragmentos. Una vez que las formas son reconstruidas, el siguiente paso es identificar a cada una de las formas. La identificación, sin embargo, es problemática puesto que muchos no prestamos la necesaria atención a este aspecto. En efecto, con mucha frecuencia las terminologías empleadas para identificar a las diferentes variantes de vasijas no sólo carecen de una definición, sino que también se acostumbra a emplear identificaciones que ni siquiera tienen una variante en el repertorio etnográfico. Al identificar vasijas de cerámica se debe hacer el máximo esfuerzo de recurrir a la evidencia etnográfica local para que ésta sirva como punto de partida de toda identificación. Éste es un paso importante, razón por la cual en las líneas que siguen se hace una referencia a dicha información.

Para la identificación de las varias formas de vasijas y sus funciones, aquí se adoptan las categorías descritas por Arnold (1993; Valdez 1997:72), considerando que dichas observaciones están basadas en la etnografía local. En otras palabras, las observaciones de Arnold (1993) en relación a la forma y función de las vasijas son aplicadas a este estudio como un análogo para inferir la función de la colección de cerámica proveniente de Marayniyoq.

Brevemente, los habitantes del valle de Ayacucho practican un tipo de agricultura de subsistencia. Dicha agricultura está orientada generalmente al cultivo del maíz y es complementado por otros productos locales u obtenidos de regiones vecinas mediante el intercambio (Valdez 1997). Así como en otros lugares (ver Arthur 2002:334), "tradicionalmente" en el valle de Ayacucho diferentes formas de vasijas de cerámica son utilizadas para procesar diferentes comidas utilizadas en la vida cotidiana.

De todo el repertorio de cerámica manufacturada, por lo general la función de una vasija es determinada por su forma y tamaño. La colección de vasijas en su conjunto es utilizada para cumplir funciones tales como cocinar, servir, transportary almacenar. De este modo, muchas vasijas son destinadas a cumplir funciones específicas; sin embargo, existen excepciones. Por ejemplo, una olla (o manka), originalmente manufacturada para preparar las comidas, puede también cum- 
plir una función secundaria y ser utilizada como granero. De igual modo, vasijas originalmente destinadas para transportar agua u otras bebidas, una vez rajadas pueden transformarse en graneros. Cuando esto ocurre, la función inicial de una vasija es fácilmente abandonada y reemplazada por una del todo diferente. Estas son observaciones importantes que merecen la atención toda vez que se discuta temas similares abordadas en este trabajo.

En el valle de Ayacucho existen dos grupos de vasijas: una compuesta por vasijas abiertas y otra por vasijas cerradas. Cada uno de estos grupos tiene sus respectivas variantes y de acuerdo a la función que cumplen reciben una identificación. El Cuadro 1 ilustra a ambos grupos y sus respectivas variantes.

\section{Vasijas cerradas}

La vasija más grande entre las pertenecientes a este primer grupo es el urpu (Valdez 1997:72). Este puede alcanzar un tamaño de $1.10 \mathrm{~m}$, con un ancho máximo que oscila alrededor de los $70 \mathrm{~cm}$. Presenta un cuello ligeramente corto y angosto que termina en labios divergentes; el cuerpo es globular, aunque ligeramente extendido hacia sus polos, y termina en una base relativamente angosta que puede ser plana o cónica. A la altura superior intermedia del cuerpo aparecen dos asas cintadas en forma horizontal. Vasijas de este tipo sirven por lo común como graneros y ocasionalmente para fermentar la chicha. Este tipo de vasijas permanecen estables en lugares específicos al interior de la residencia doméstica; como resultado, su ciclo de vida puede ser prolongado.

La siguiente vasija cerrada viene a ser el qipiri (Valdez 2002a:78). Éste puede tranquilamente alcanzar un tamaño de $80 \mathrm{~cm}$, con un ancho máximo que oscila alrededor de los $55 \mathrm{~cm}$. En realidad, éste viene a ser una versión más pequeña de la forma anterior; como tal, ambos se asemejan bastante. Sin embargo, además de la diferencia en el tamaño, qipiris se caracterizan por tener una base predominantemente cónica y dos asas cintadas verticales colocadas en forma asimétrica a la altura superior media del cuerpo. Esto quiere decir, que las asas están más próximas en un lado de la vasija. Dicha posición de las asas explica que estas vasijas fueron manufacturadas para ser cargadas en la espalda de los individuos. La parte donde el espacio entre las asas es más próxima, descansa sobre la espalda de la persona que la carga. Qipiris sirven para transportar bebidas como el agua o en su defecto la chicha. Por cuanto el qipiri está en permanente movimiento, su ciclo de vida es corto. Algunas pueden ser restauradas; cuando esto ocurre, la función original de las vasijas cambia. En lugar de servir para el transporte de bebidas, son utilizadas como graneros, al igual que el urpu.

La tercera variante de vasijas cerradas está formado por el tumin. Ésta viene a ser una versión pequeña del urpu. Ocasionalmente puede tener el mismo tamaño que el qipiri, pero está asociada con el almacenamiento de granos. Desde luego puede ser utilizada para fermentar bebidas como la chicha, pero ésta no es transportada al

Cuadro 1. Formas de vasijas de acuerdo a la evidencia etnográfica local.

Vasijas cerradas
Urpu
Qipiri
Tumin
Aysaku
Lluku puyñu

Vasijas abiertas
Maqma
Aqa Maqma
Tinaja
Manka
Toqto


contrario de qipiri. Como tal, el ciclo de vida de estas vasijas tiende a ser relativamente larga.

La cuarta variante de vasijas cerradas está conformada por el aysaco o puyñu. Ésta es de tamaño pequeño, el mismo que puede variar entre 30 y $50 \mathrm{~cm}$. Presenta un cuello angosto, lugar donde aparece por lo general una asa cintada vertical. El cuerpo es relativamente globular y termina en una base plana. Su función principal es para transportar agua, aunque ocasionalmente pueden servir para guardar semillas.

Finalmente, la quinta forma de vasijas cerradas está compuesta por el lluku puyñu. Ésta no supera los $40 \mathrm{~cm}$ de tamaño. Se caracteriza por su cuello ligeramente largo y angosto. También sirve para transportar agua. Al igual que la forma anterior, tiene un ciclo de vida corta precisamente por estar en constante movimiento.

\section{Vasijas abiertas}

La vasija más grande entre las pertenecientes al segundo grupo es la maqma (Valdez 1997:72). La cual puede alcanzar un tamaño de $1.10 \mathrm{~m}$, con un ancho máximo que oscila alrededor de los $70 \mathrm{~cm}$. Presenta un cuello corto que es relativamente abierto y que termina en labios divergentes. Por lo común, pasa una cuerda o soga a la altura del cuello y sirve de soporte para que la vasija no se rompa por la presión del contenido. El cuerpo es globular, ligeramente extendido hacia sus polos, y termina en una base angosta que puede ser plana o cónica. A la altura superior intermedia del cuerpo aparecen dos asas cintadas en forma horizontal. Vasijas de este tipo sirven por lo común como graneros y para fermentar la chicha. Una destinada a la fermentación de la chicha, conocida como sinka (o borracha), normalmente no es utilizada como granero. Este tipo de vasijas permanecen estables en lugares específicos al interior de la residencia doméstica; como resultado, su ciclo de vida es larga.

Una variación del anterior viene a ser la aqa maqma. En todos sus aspectos, ésta es idéntica a la anterior excepto que esta última está destina- do a cumplir una función específica, la misma que es la preparación de la chicha de molle (Terrell, et al., 2003:342). La notable diferencia es la presencia de un pequeño orificio aproximadamente a $10 \mathrm{~cm}$ de la base. En esta vasija se remojan las semillas del molle por aproximadamente tres horas; el objetivo es extraer el dulce de dichas semillas. Luego, utilizando el pequeño orificio, se filtra el agua endulzada del interior de la aqa maqma. Dicho líquido endulzado es luego fermentado en urpus y maqmas. Sin ubicar el pequeño orificio, sería difícil identificar una aqa maqma; en consecuencia, ésta fácilmente podría ser reconocida como maqma y así se estaría adjudicándosele una función errada. A diferencia de la forma anterior, el ciclo de vida de este tipo de vasijas es corto.

La siguiente vasija abierta está representada por la tinaja. Tiene aproximadamente el mismo tamaño del qipiri, y constituye una versión pequeña de la maqma. Por lo general, por lo menos aquellos que siguen en uso, presentan una base plana y dos asas en posición vertical colocadas en forma simétrica en la parte superior media del cuerpo. Al igual que la maqma, la tinaja sirve para depositar granos y fermentar la chicha. Su tamaño pequeño hace que esta vasija sea fácilmente transportada de un lugar a otro, aunque generalmente en la misma unidad doméstica. Como resultado, su ciclo de vida es relativamente corto en comparación a la maqma.

Siguiendo en forma descendiente, la siguiente vasija abierta está representada por la manka u olla. Vasijas de esta clase son de diversos tamaños, pero todas son más pequeñas que la tinaja. Mientras que la maqma y la tinaja presentan cuerpos ligeramente extendidos hacia sus extremos superior e inferior, la manka es más globular. Además, una característica fundamental de la manka es su base redondeada y un cuello corto. En algunos casos, dos o incluso cuatro asas verticales aparecen precisamente entre el borde y la parte inferior del cuello. Otras tienen sus asas en la parte superior media del cuerpo. Vasijas de este grupo sirven para preparar las comidas, aun- 
que ocasionalmente pueden cumplir la función de graneros. Por cuanto son utilizadas continuamente, el ciclo de vida de una manka es bastante corto.

En general, éstas son las diversas formas de vasijas comunes en el valle de Ayacucho. Desde luego hay algunas formas adicionales, pero que no siempre tienen su forma correspondiente en contextos arqueológicos. Teniendo las formas aquí definidas, se discute a continuación la variación de las vasijas provenientes de Marayniyoq. La función de cada una de dichas formas también se discute teniendo en consideración las observaciones brevemente referidas líneas adelante.

\section{Forma y función de la cerámica de Marayniyoq}

Siguiendo el hallazgo de varias piedras trabajadas, primero en 1999 (Valdez, et al. 1999, 2001), luego en 2001 (Valdez 2002a, Valdez, Bettcher \& Valdez 2002) y finalmente en 2002 (Valdez 2002b, 2003) se efectuaron las excavaciones arqueológicas en el sitio Wari de Marayniyoq. Los trabajos fueron orientados a definir tanto la función, como la asociación cultural de las piedras trabajadas. Para su efecto, el lugar donde las piedras fueron expuestas fue cuadriculado, estableciéndose varias unidades de 5 X 5 metros de dimensión. Las unidades fueron orientadas en referencia a dos coordenadas transversales (Este-Oeste y Norte-Sur). En el punto de intersección de las líneas se instaló la cota como punto de referencia topográfica.

El sector excavado presenta una superficie bastante alterada como resultado de las contemporáneas actividades humanas en el lugar. Mientras una buena porción del sector excavado venía siendo explotado como lugar de pastoreo, áreas inmediatas ya venían siendo utilizadas para la agricultura. En consecuencia, la estratigrafía no es del todo uniforme. Por ejemplo, en algunas unidades un piso compacto fue expuesto inmediatamente después de excavar un nivel. En otros, el mismo piso fue expuesto luego de retirar dos o hasta tres niveles.
Debido a esa variación estratigráfica, el piso en referencia sirve como base diagnóstica para interpretar la estratigrafía del sitio, especialmente considerando que dicho piso aparece en todas las unidades excavadas. Cabe anotar que el análisis de una muestra del piso, efectuado por Octavian Catuneanu, del departamento de Suelos y Ciencias Atmosféricas de la Universidad de Alberta (Canadá), reveló que una mezcla de diatomita y ceniza volcánica fue empleada para la construcción del piso. Dicho material, de acuerdo a las observaciones hechas en el campo por Andrés Portugal Paz, de la facultad de Minas, Geología y Civil de la Universidad de Huamanga (Ayacucho), está presente en las mismas inmediaciones del sitio. Esto indica que en la construcción de Marayniyoq, se utilizaron materiales localmente disponibles.

Los fragmentos de cerámica pertenecientes a vasijas ocurren en la mayoría de las unidades excavadas; sin embargo, solamente algunas piezas provenientes de seis diferentes espacios físicos fueron posibles de restaurar en forma parcial. Todas estas concentraciones de cerámica fragmentada fueron halladas sobre el piso compacto. Dichos espacios físicos son considerados a continuación.

La primera concentración de cerámica fragmentada se expuso al lado Nor-Oeste del sector excavado, denominado Ambiente 1 (Figura 2). Este fue el lugar inicialmente arrasado por el tractor, exponiendo en algunos lugares el piso compacto, además de algunas piedras trabajadas. El ambiente, sólo parcialmente definido, está compuesto por dos muros paralelos ubicados al lado sur de un espacio que parece haber sido amplio y dotado de un piso compacto. Al lado Este de dicho ambiente aparece otro muro parcialmente conservado. Al lado opuesto hay un muro que también se proyecta hacia el Norte; dicho muro probablemente formó parte de este espacio físico. Al "interior" de este espacio y siempre sobre el piso compacto se hallaron varias concentraciones de cerámica fragmentada. Puesto que muchas de éstas fueron parcialmente restaura- 


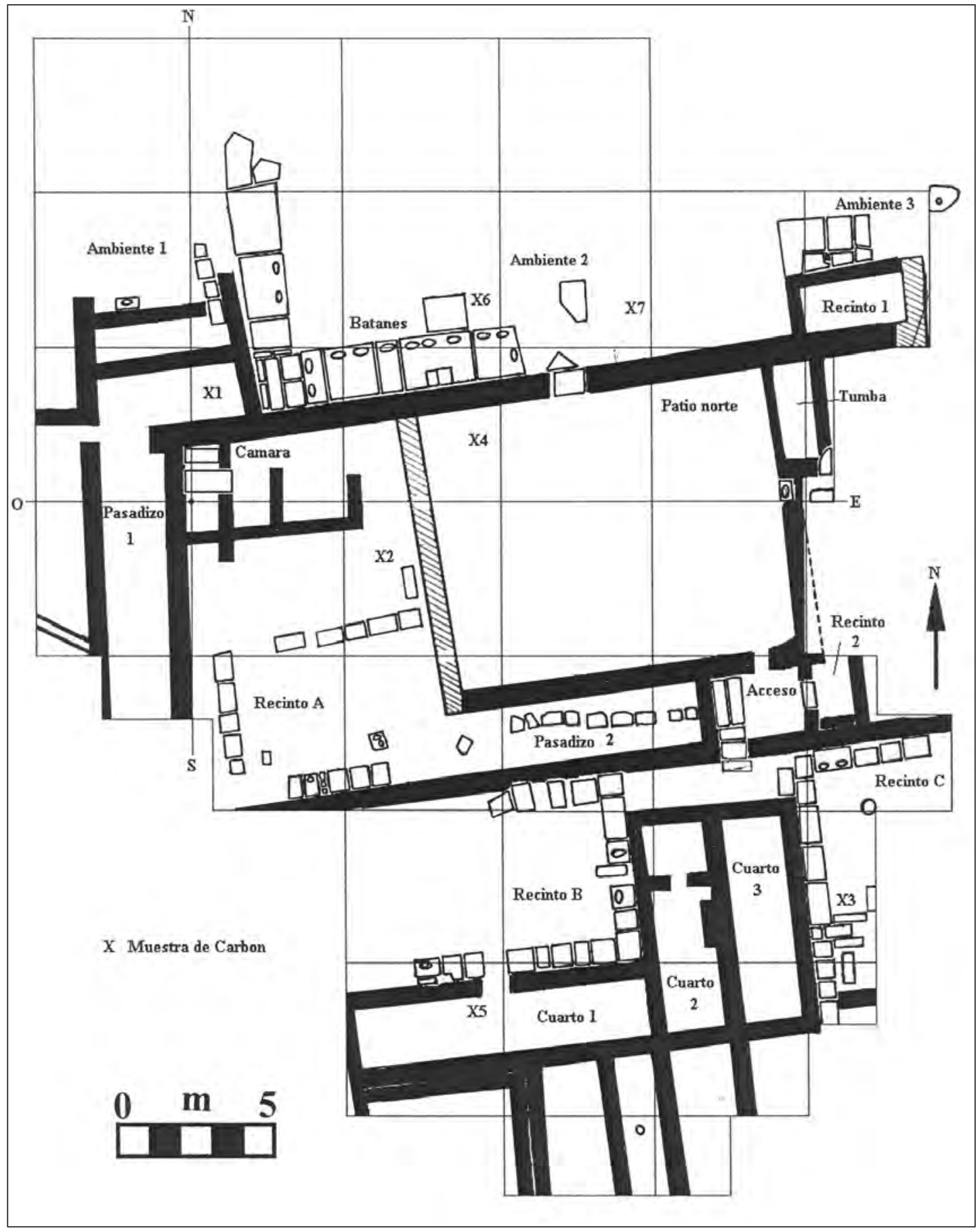

Figura 2. Plano del sector excavado de Marayniyoq. La $X$ indica la proveniencia de las muestras de carbón. 


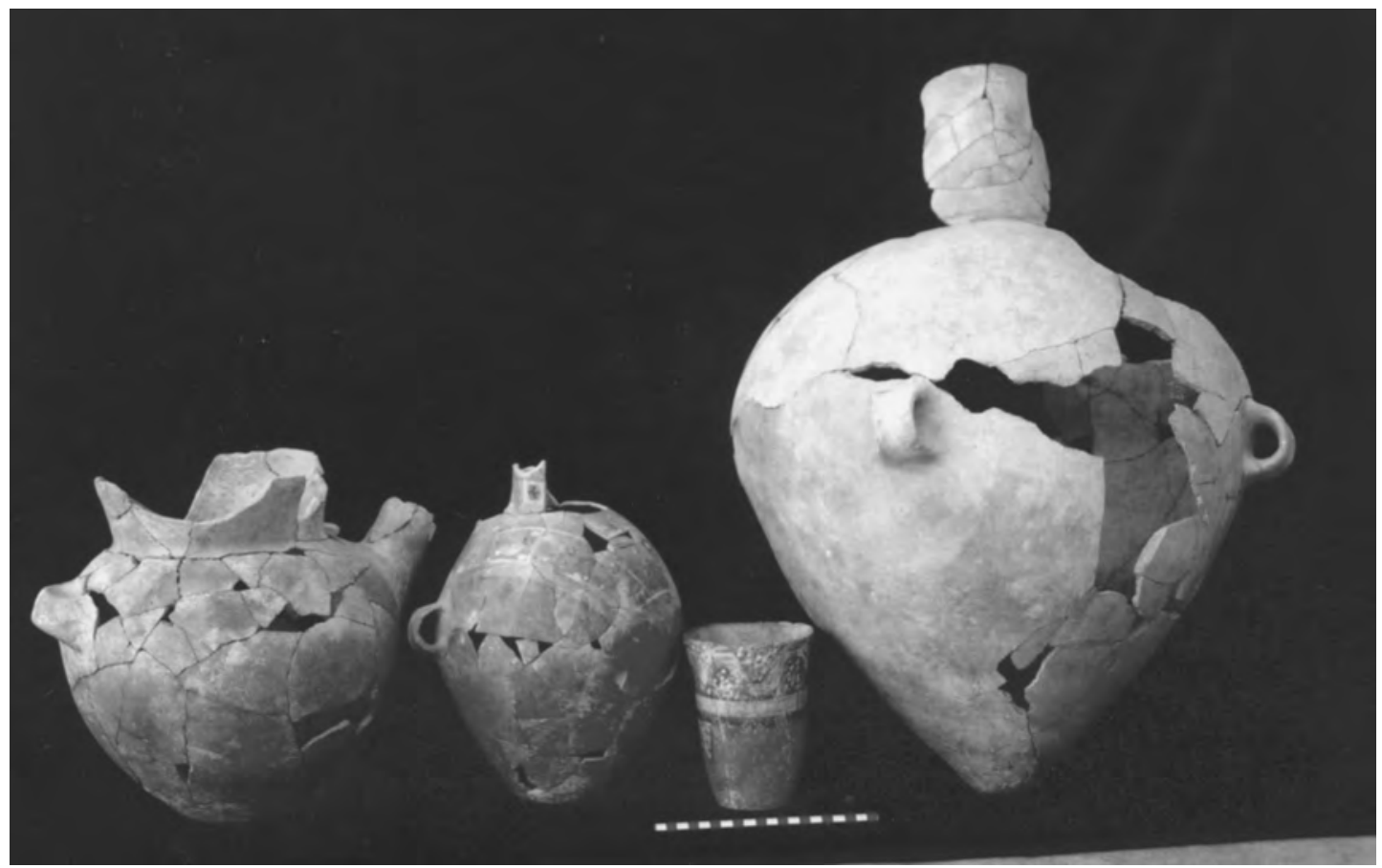

Figura 3. Grupo de vasijas halladas sobre el piso compacto del Ambiente 1.

das (Figura 3), existe la posibilidad que tales vasijas fueron halladas en el mismo lugar donde originalmente fueron depositadas cumpliendo una función determinada. En efecto, el piso presenta varios hoyos que probablemente fueron los lugares donde las vasijas han estado establecidas. Interesante es anotar que las vasijas grandes tienen bases cónicas. Junto a una de éstas concentraciones de cerámica fragmentada también se halló una molienda (tunay) bien pulida que estaba en directa asociación a un kero decorado en el estilo Wamanga (Valdez, et al., 2000:554-555). A corta distancia, al sur de la molienda, se expuso un batán consistente de una piedra trabajada de forma rectangular que como característica principal presenta una depresión pronunciada sobre su superficie. Un alineamiento de cuatro piedras trabajadas, dos de las cuales también tienen depresiones, fueron expuestas al lado Este. Del mismo modo, en el pequeño espacio, entre los dos muros paralelos del lado sur, se hallaron otras concentraciones similares; una de éstas es la parte inferior de una vasija grande que todavía mantenía una posición vertical. El caso de los batanes de discutirá brevemente más adelante.

Una segunda concentración de cerámica fragmentada se expuso en el pasadizo estrecho formado por dos muros paralelos ubicados inmediatamente al sur del Ambiente 1. El pasadizo mantiene una orientación de Norte-Sur (Pasadizo 1), tiene un piso compacto y paredes enlucidas de blanco; sobre este piso se hallaron los fragmentos de vasijas de cerámica, varias de las cuales fueron también parcialmente restauradas. En un caso, se pudo observar la parte inferior de una vasija grande de base cónica aún manteniendo su probable lugar original, mientras que sus fragmentos estaban en las inmediaciones. Fragmentos de utensilios, decorados en el estilo Wamanga, también fueron hallados en el mismo contexto (Figura 4).

La tercera concentración de cerámica fragmentada fue descubierta solo a corta distancia del ambiente anterior. Efectivamente, al Sur- 


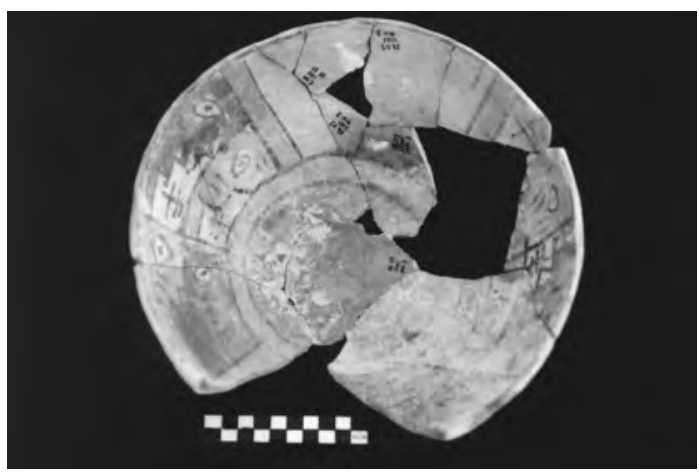

Figura 4. Vajilla decorada en el estilo Wamanga proveniente del Pasadizo 1 (sobre el piso).

Este del pasadizo se expuso un pequeño recinto compuesto por varias piedras trabajadas. Para los propósitos de esta discusión, este nuevo ambiente es considerado como Recinto A (Figura 2). Al interior de dicho recinto y siempre sobre el piso se expuso una acumulación de cerámica fragmentada (Figura 5). Nuevamente, varias vasijas fueron parcialmente restauradas. Muchas son vasijas grandes que parecen haber sido destrui- das en el mismo lugar donde originalmente cumplieron alguna función. Corroborando esta observación, se halló una vasija de base cónica parcialmente completa manteniendo una posición vertical y probablemente en el mismo lugar donde antiguamente fue colocada. Otras vasijas también fueron en parte restauradas, sugiriendo una vez más que dichas vasijas fueron destruidas in situ. Cabe resaltar, al mismo tiempo, que una pequeña pieza de cerámica muy bien decorada fue hallada entre los fragmentos (Figura 6). Esta también estaba fragmentada. Algunos de sus fragmentos fueron recuperados sobre el piso del pasadizo previamente referido, lo que sugiere que ambos ambientes, y por lo tanto las acumulaciones de cerámica, son contemporáneos. Patricia Knobloch identificó a este ejemplar como Chakipampa B. Una muestra (TO-11013) de carbón recuperado de las inmediaciones de este hallazgo y siempre sobre el piso compacto arrojó un fechado de 885-995 d.C. (calibrado a un sigma).

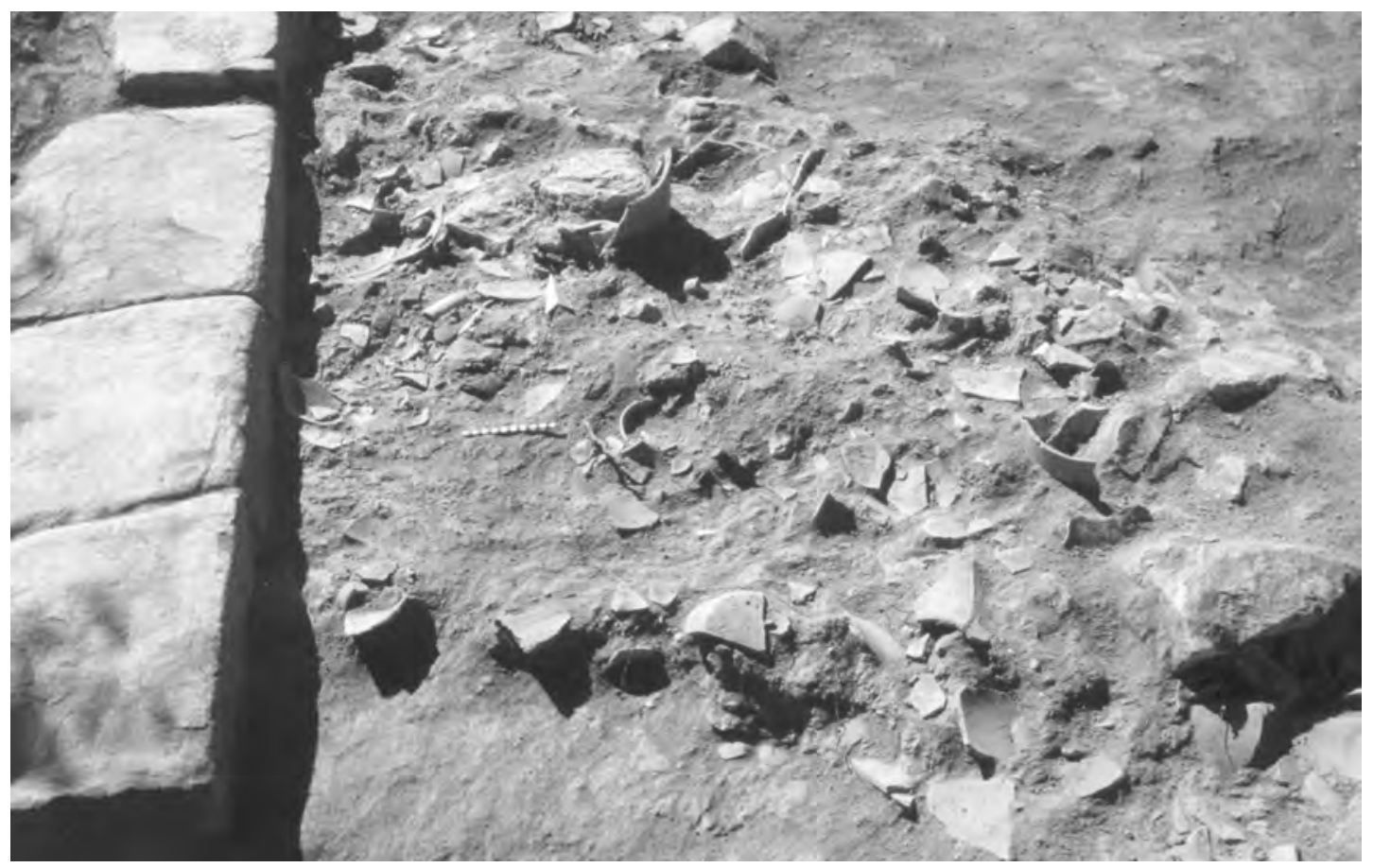

Figura 5. Detalle de la concentración de cerámica fragmentada al interior del Recinto A. 


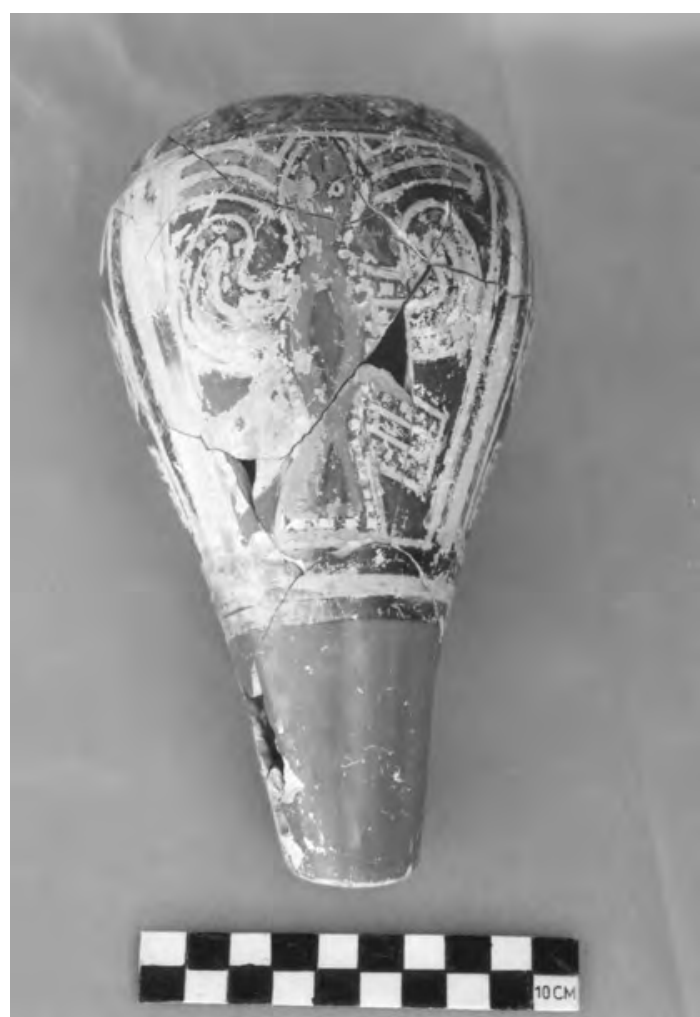

Figura 6. Cerámica policroma (Chakipampa 1B) cuyos fragmentos fueron hallados sobre el piso del Recinto A y del Pasadizo 1.

Una cuarta, aunque pequeña concentración, se expuso en el ambiente denominado Pasadizo 2 (ver Figura 2). Siempre sobre el piso compacto y pegado al muro del lado sur, se hallaron dispersos fragmentos pertenecientes a vasijas grandes. Ninguna de las vasijas fue posible restaurar. Sin embargo, parece que varias vasijas habían estado instaladas apoyadas al muro sur del referido pasadizo. Se debe anotar que en la parte central del pasadizo hay un total de diez piedras planas de forma irregular colocadas en forma alineada, y que al parecer sirvieron para dar acceso al Recinto A.

Una quinta acumulación de cerámica fragmentada fue hallada en el ambiente identificado como Cuarto 3 (Figura 2). Éste es un ambiente de forma rectangular, ubicado al lado este de otro ambiente bastante parecido. Al interior de dicho ambiente y siempre sobre un piso bastante compacto, aunque ligeramente deteriorado, se expuso una concentración de vasijas rotas; una de éstas pertenece a una vasija grande.

Otra acumulación de cerámica fragmentada se halló en el espacio identificado como Recinto C, ubicado al este del Cuarto 3 (Figura 2). Como en los casos anteriores, los fragmentos de cerámica fueron hallados sobre un piso bastante compacto y al interior de una estructura similar al Recinto A. Una muestra (TO-11014) de carbón recuperado de las inmediaciones de este hallazgo y siempre sobre el piso compacto arrojó un fechado de 770-895 d.C. (calibrado a un sigma). Una estructura similar a estos dos se encuentra entre ésta y el Recinto $\mathrm{A}$ y es denominado como Recinto B. Este último fue descubierto, a diferencia de los anteriores, relativamente limpio. En el Recinto C, además, se halló un respiradero de un sistema de canales subterráneos. El referido respiradero estaba cubierto por una laja con un pequeño orificio en su parte central; dicho orificio, a su vez, estaba cerrado por un tapón de piedra trabajada. Dicha cubierta había sido colocada a nivel del piso del recinto. Sobre la cubierta del mencionado respiradero se había depositado gran cantidad de cerámica fragmentada. Muchos de los fragmentos hallados en este recinto pertenecen a utensilios y entre estas algunas vasijas.

En la sección este del Cuarto 1 también se expuso una concentración de cerámica fragmentada, pero ninguna fue restaurada. Los fragmentos pertenecen a utensilios, algunos de los cuales decorados. También fueron hallados, sobre el piso compacto parcialmente deteriorado, huesos de un camélido joven, un fragmento de obsidiana y una valva completa de un bivalvo marino (Choromytilus chorus). Una muestra (TO11017) de carbón recuperado del interior de este ambiente y siempre sobre el piso compacto arrojó un fechado de 895- 920 d.C. (calibrado a un sigma). Merece mención que por debajo de este piso se descubrió un piso anterior; por debajo de aquel piso pasa un canal en dirección Nor- 
Oeste. Las paredes de este cuarto presentan un enlucido blanco. Una serie de estructuras solo parcialmente expuestas se encuentran al lado sur de este cuarto.

En general, estas son las mayores concentraciones de cerámica fragmentada halladas mediante las excavaciones efectuadas en Marayniyoq. Puesto que muchos de los fragmentos hallados concentrados podían ser unidos, durante el proceso del análisis se decidió efectuar la restauración de varias piezas. La Figura 7 ilustra las diversas formas reconstruidas, mientras que el Cuadro 2 presenta la distribución de las mismas. Las vasijas parcialmente restauradas sirven como punto de partida para identificar las diversas formas y sus probables funciones. Esta reconstrucción deja obvio que en Marayniyoq se utilizaron diversas formas de vasijas, muchas de las cuales eran de gran tamaño.

En primer lugar, no todas las formas presentes en el repertorio etnográfico se encuentran en la colección de cerámica de Marayniyoq. El más obvio tal vez es la ausencia de vasijas identificables como urpu. En su lugar, y tal como se ilustra en la Figura 7, hay tres formas de maqmas, definidas en base a sus formas relativamente distintas. Estas, son a su vez las formas más grandes de toda la colección de cerámica de Marayniyoq. La primera variedad identificada como Maqma A (Figura 7A) es la más común en Marayniyoq; se caracteriza por su cuello bastante corto y sus asas cintadas dispuestas en forma horizontal, y colocadas en la parte superior media del cuerpo. En base a la forma del borde, inicialmente se pensó que esta forma representaba a una olla o manka, pero la restauración de algunas muestras hizo posible definir que ésta es una maqma. La segunda forma ha sido identificado como Maqma B (Figura 7B); de ésta solo un ejemplar fue parcialmente restaurado y proviene del Recinto A. A diferencia de la primera variación, esta presenta un cuello ligeramente largo y recto y dos asas dispuestas en forma vertical. La tercera variación de maqma (Maqma C) está representado por una vasija también de tamaño grande, cuello relativamente largo, bordes divergentes, tres asas dispuestas en forma vertical y una base -a diferencia de las dos anteriores-plana (Figura 7C). El único ejemplar fue hallado roto, luego restaurado, al interior del Cuarto 3.

Las siguientes formas de vasijas abiertas están representadas por un grupo de vasijas bastante similares a las maqmas, a diferencia que éstas son de tamaños más pequeños (Figuras $7 \mathrm{D}$, E, F, Gy H) e identificables como tinajas. En realidad, vienen a ser modalidades pequeñas de la maqma y como tales cumplen funciones similares a éstas. Aunque un número bastante reducido de vasijas de esta categoría fueron posibles restaurar, la presencia de bordes pertenecientes a tinajas sugiere que este grupo fue bastante común en Marayniyoq. Al igual que muchas vasijas gran-

Cuadro 2. Distribución espacial de las varias formas de vasijas restauradas

\begin{tabular}{lccccccc}
\hline & Qipirig. & Qipirim. Llukupuyñu & Maqma A & MaqmaB Maqma & C & Tinaja \\
Ambiente 1 & 4 & 1 & - & 2 & - & - & $1^{*}$ \\
Pasadizo 1 & 1 & - & - & 2 & 1 & - & 1 \\
Recinto A & 4 & 3 & - & 2 & - & 1 & 2 \\
Recinto C & 1 & - & 1 & - & - & - & 1 \\
Cuarto 3 & - & 2 & - & 1 & - & - & - \\
TOTAL: & $\mathbf{1 1}$ & $\mathbf{6}$ & $\mathbf{1}$ & $\mathbf{7}$ & $\mathbf{1}$ & $\mathbf{1}$ & $\mathbf{5}$ \\
\hline
\end{tabular}

* Esta tiene la forma de una tinaja, pero cuenta con una sola asa cintada horizontal y un pico precisamente al lado opuesto del pico. Su función por lo tanto debió haber sido distinta al de una tinaja. 


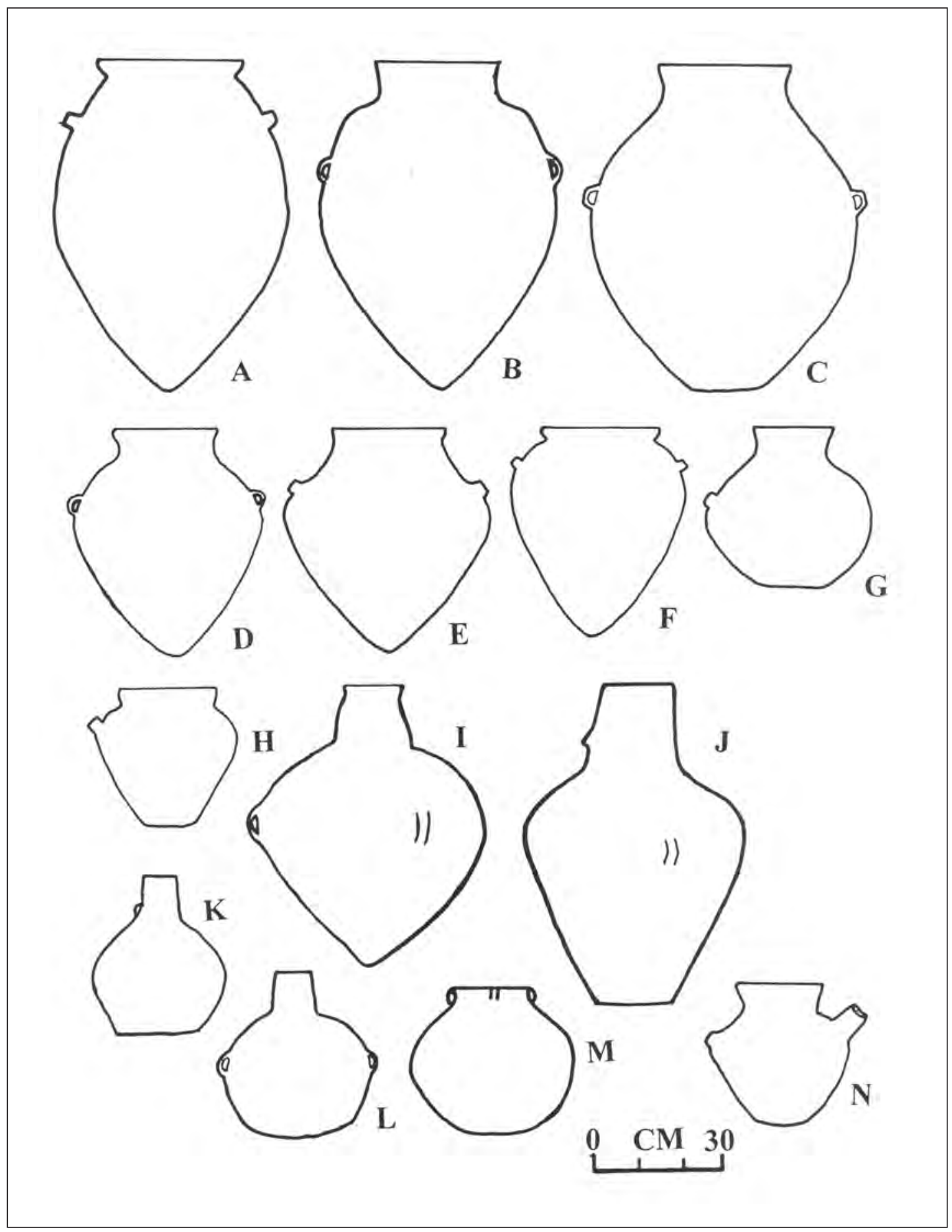

Figura 7. Diversas formas reconstruidas para la colección de vasijas de Marayniyoq. 
des, muchas de las tinajas presentan una base cónica. Las únicas que tienen una base plana son las de tamaños más pequeños. Esto sugiere que las tinajas, al igual que las maqmas, permanecieron por lo general en lugares específicos, conteniendo posiblemente algún grano. Una vasija también identificable como tinaja, pero que obviamente cumplió una función distinta, está presente en la colección de Marayniyoq. Se trata de una vasija abierta, de tamaño pequeño, con una asa cintada horizontal y un pico ubicado al lado opuesto de el asa (Figura 7N). Esta vasija, como se discute adelante, debió haber sido útil para servir las bebidas.

Por su lado, las vasijas cerradas están representadas por qipiris. Entre estos están las qipiris grandes y de manufactura simple (Figura 7I). Todas presentan una base cónica, cuerpo ovoide aunque ligeramente expandido en su parte media superior, y dos asas verticales siempre dispuestas asimétricamente. Una excepción viene a ser la notable variación en la forma de los cuellos; algunos son rectos, otros relativamente expandidos en su parte media y unos terceros convergentes. Sin embargo, una mayoría de los bordes están reforzados del lado exterior, haciendo que estos sean relativamente anchos. Vasijas de esta variedad aparecen en tamaños grandes y pequeños; su base notablemente cónica sugiere que esta variedad de qipiris por lo general permanecieron estables en lugares específicos, desde luego conteniendo bebidas. La superficie externa de la sección de la base presenta muchas estrías, indicando nuevamente que vasijas de base cónica (incluyendo las maqmas) permanecieron en hoyos.

Al lado de los qipiris pobremente manufacturados y que nunca fueron decorados, hay otras que si recibieron un mejor tratamiento tanto en su producción, como en su acabado final. Efectivamente, estas fueron continuamente decoradas al igual que los keros. El cuello se caracteriza por lo general por la presencia de una "cara gollete", que a menudo representa a un personaje masculino. Los ojos, la nariz, la boca y las orejas fueron moldeados y luego pintados (ver Figuras 8 y 9).
Patricia Knobloch identificó a este ejemplar como perteneciente al estilo Viñaque. Una diferencia adicional en relación a los que nunca fueron decorados es que estos últimos presentan una base cónica (Figuras 7Jy 10). Por lo tanto, la única similitud entre estas dos variaciones es la disposición de las asas, que siempre son verticales, pero asimétricamente colocadas (ver Figura 10).

Por último, aparecen un grupo de vasijas identificables como lluku puyñu o simplemente como botellas (Figuras $\mathrm{K}$ y L). Estas son por lo general de color negro, pero no son comunes en la colección de Marayniyoq. Además de su notable cuello largo y angosto, presentan un cuerpo globular que termina en una base plana. Algunas presentan una pequeña asa, mientras otras tienen dos asas simétricamente ubicadas.

Una forma que resalta por su ausencia en la colección de cerámica de Marayniyoq son las mankas. De manera especial, aquellas que son ideales para preparar las comidas y bebidas en can-

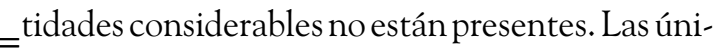
cas encontradas son mankas de tamaños pequeños (Figura 7M). Esta ausencia sugiere, tal como se discute más adelante, que en Marayniyoq no se procesaron las comidas y bebidas en cantidades considerables. Aquellas utilizables en el hervido y preparación de comidas y bebidas son en efecto muy pequeñas y como tales sus funciones debieron haber sido distintas; efectivamente, estas tal vez fueron las utilizadas por el personal que laboró en Marayniyoq para preparar sus alimentos de manera individualy/o separada.

Junto a las vasijas que pudieron ser restauradas por lo menos en parte, se hallaron otras concentraciones más pequeñas que generalmente corresponden a vasijas aisladas. Uno de tales hallazgos viene a ser la acumulación de cerámica finamente decorada precisamente en el pasadizo ubicado inmediatamente al norte del Cuarto 3. Este hallazgo consiste de la porción superior de una vasija cerrada de tamaño grande (qipiri). Partes del cuerpo y la base no estaban presentes. La vasija está decorada en el estilo Viñaque del Horizonte Medio 2. A la altura del gollete apare- 


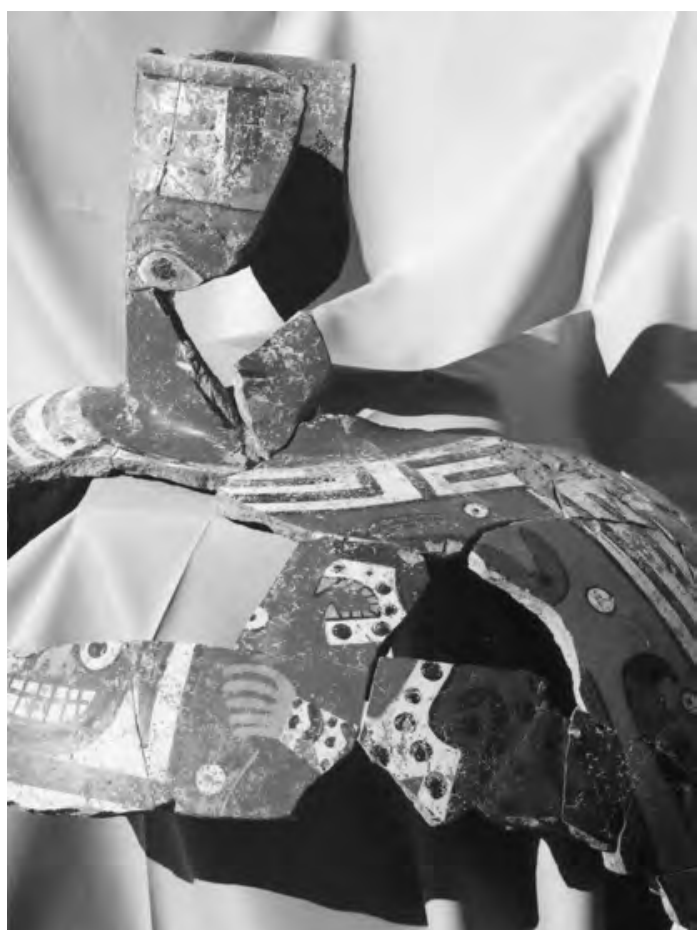

Figura 8. Vasija cerrada y decorada (Viñaque del HM2) proveniente del espacio ubicado inmediatamente al norte del Cuarto 3.

ce la representación de un personaje masculino. Tanto los ojos, la boca, nariz y las orejas fueron moldeados y pintados (Figura 8). Entretanto, a la altura del pecho se observa a dos figuras antropomorfas que representan a dos felinos que apare- cen con las bocas abiertas. Finalmente, en el espacio entre dichas representaciones aparecen dos caras antropomorfas femeninas (Figura 9). Desafortunadamente, el resto de la representación es difícil de apreciar por cuanto no todas las piezas fueron halladas.

Hallazgos similares al previamente descrito, aunque no de vasijas finamente decoradas, ocurren a lo largo del área excavada. Por ejemplo, a los lados norte y este del grupo de bloques de piedra trabajada que presentan depresiones (al este del Ambiente 1) se hallaron dos qipiris de tamaños medianos, además de tres cuellos de qipiri y una base cónica. En consecuencia, el sector excavado de Marayniyoq estaba repleto de fragmentos de cerámica pertenecientes por lo general a vasijas grandes y de diferentes formas. El Recinto B, el Cuarto 2 y el lado norte del área excavada son las únicas áreas donde no se hallaron evidencias parecidas. El ambiente identificado como Patio, excepto su lado norte, también estaba relativamente vacío.

Tal como se anotó líneas adelante, fragmentos de cerámica pertenecientes a vasijas grandes ocurren en otros lugares de la excavación y siempre sobre el piso compacto. Un buen número de dichos fragmentos fueron hallados en los mismos contextos que las vasijas restauradas, mientras que otros fueron hallados en lugares diferentes,
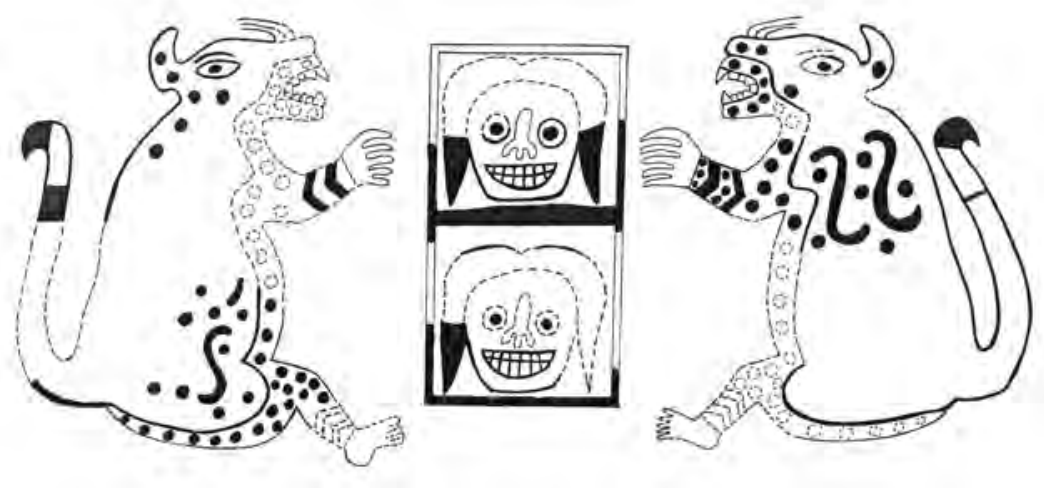

Figura 9. Detalle de dos representaciones (felinos) presentes en la parte delantera de la vasija de la Figura 8. 


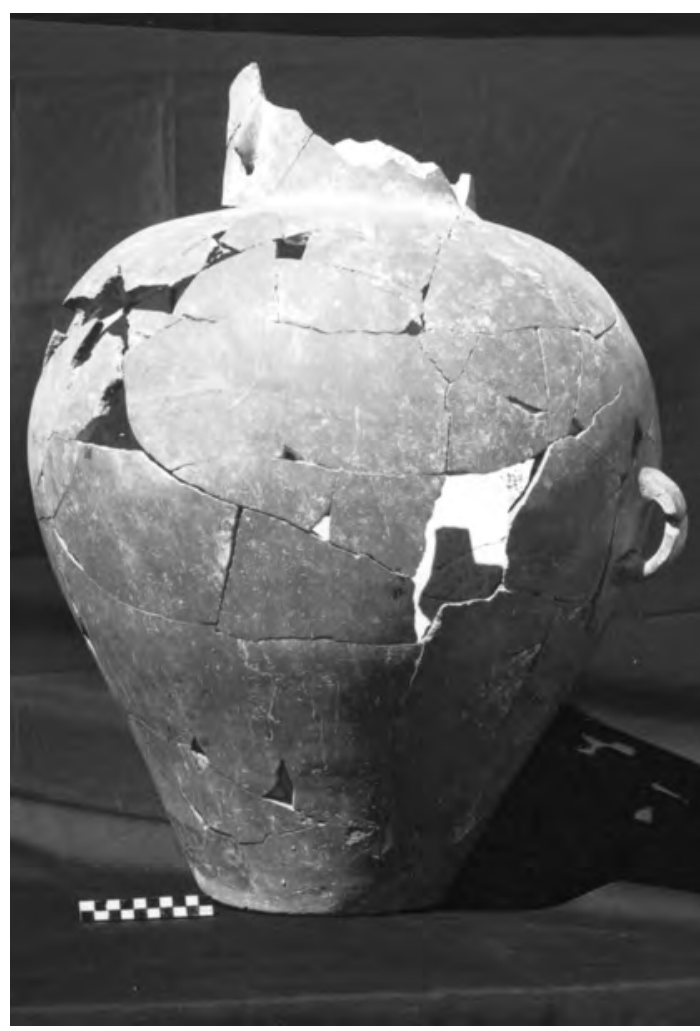

Figura 10. Qipiri restaurado y decorado proveniente del recinto $A$. pero siempre sobre el piso y concentrados. En referencia a las formas restauradas (Figura 7), los diversos bordes fueron identificados en cuanto a forma se refiere; la distribución de las mismas aparece en el Cuadro 3. Con todo esto y algunos datos presentados más adelante, se puede tener una idea más o menos general de la actividad efectuada en Marayniyoq.

De los resultados presentados en los Cuadros 2 y 3 se desprende con suma claridad la alta concentración de vasijas en Marayniyoq. De manera especial, existe un predominio de vasijas identificables como maqma, tinaja y qipiri, formas éstas asociadas, de acuerdo a la analogía, con el almacenamiento de granos y la fermentación y transportación de bebidas, como la chicha. En otro trabajo ya se adelantaron algunas ideas concernientes a la posible utilización de dichas vasijas en la fermentación y transportación de la chicha (ver Valdez 2002), razón por la cual aquí no se hace intento alguno a repetir dicho argumento.

Sin embargo, es oportuno anotar que tres qipiris decorados, recuperados del Recinto $\mathrm{A}$, que fueron parcialmente restaurados, ya habían sido originalmente restauradas. Otro qipiri de base cónica y como tal no decorado, proveniente del

Cuadro 3. Distribución de bordes y bases específicas de vasijas de Marayniyoq

\begin{tabular}{|c|c|c|c|c|c|c|c|c|c|}
\hline \multirow[b]{3}{*}{ Ambiente 1} & \multicolumn{3}{|c|}{ Bordes Cerrados } & \multicolumn{3}{|c|}{ Bordes Abiertos } & \multicolumn{3}{|c|}{ Bases } \\
\hline & Qipiri & Lluku риуп̃u & Риyп̃u & Maqma A & $\mathrm{MaqmaC}$ & Tinaja & olla & Cónica & Plana \\
\hline & 2 & - & - & 3 & 2 & 1 & 2 & 4 & - \\
\hline Ambiente 2 & 6 & - & - & 4 & - & 5 & - & - & - \\
\hline Ambiente 3 & 7 & 1 & 2 & 19 & 5 & 19 & 5 & 2 & 4 \\
\hline Recinto 1 & 9 & - & - & 2 & 7 & 9 & - & 1 & 1 \\
\hline Patio Norte & 12 & 1 & 1 & 24 & - & 3 & - & - & - \\
\hline Pasadizo 1 & 6 & - & - & 2 & 3 & 1 & - & 1 & 1 \\
\hline Recinto A & 12 & - & - & 12 & 12 & 1 & - & 2 & - \\
\hline Pasadizo 2 & 1 & - & 4 & 1 & - & 1 & 2 & - & 1 \\
\hline Recinto 2 & 10 & - & 2 & 9 & - & 5 & 3 & - & - \\
\hline Cuarto 1 & 4 & - & 1 & 5 & 1 & 6 & 1 & - & - \\
\hline Cuarto 3 & - & - & - & 1 & 2 & - & - & 6 & 1 \\
\hline Recinto C & 3 & 3 & 3 & 1 & 3 & 4 & - & 2 & - \\
\hline TOTAL: & 72 & 5 & 13 & 84 & 45 & 55 & 13 & 18 & 8 \\
\hline
\end{tabular}




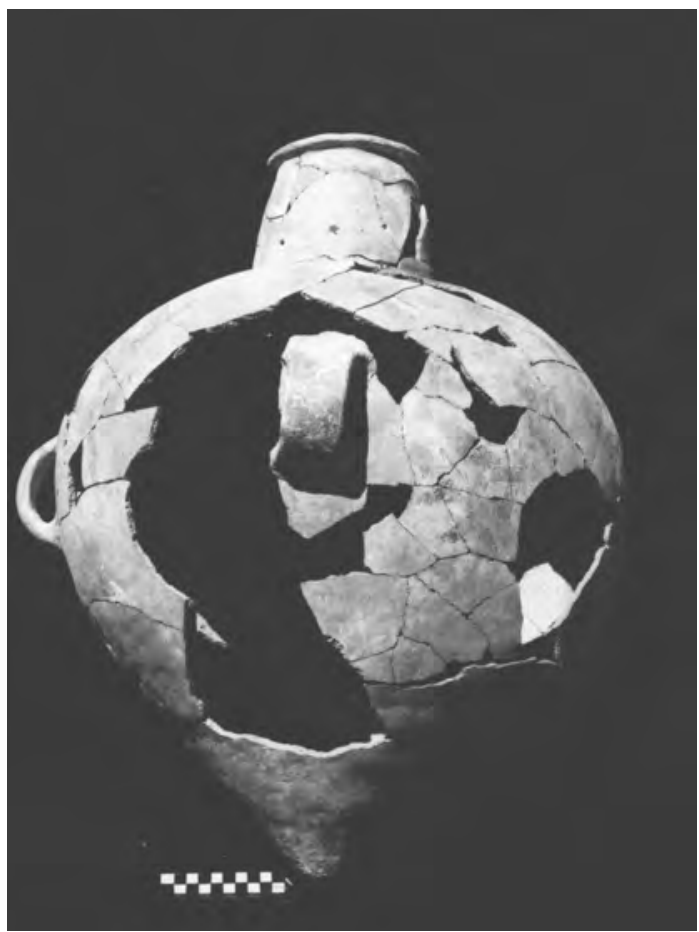

Figura 11. Qipiri de base cónica y sin decoración proveniente del Pasadizo 1.Ya había sido restaurado inicialmente.

Pasadizo 1 también había sido antiguamente restaurado (Figura 11). Finalmente, la maqma de base plana (Figura 12) hallada en el Cuarto 3 también había sido restaurada en la antigüedad. Si todas estas vasijas cumplieron las funciones para las que fueron inicialmente manufacturadas, especialmente los qipiris, dicha función debió haber sido del todo modificado una vez que las vasijas fueron restauradas. Es decir, qipiris restaurados, por ejemplo, simplemente no pudieron haber continuado siendo utilizados en la transportación de bebidas; mas bien, éstos debieron haber servido y seguramente sirvieron como vasijas de almacenamiento de granos o de algo similar (ver adelante). En consecuencia, encontrar vasijas decoradas y no decoradas en el mismo contexto, no debe ser de extrañar, especialmente en casos como los referidos en este trabajo.

A diferencia del qipiri finamente decorado, ilustrado en la Figura 8 y que fue ubicado aislado, el resto de las vasijas decoradas y no decoradas

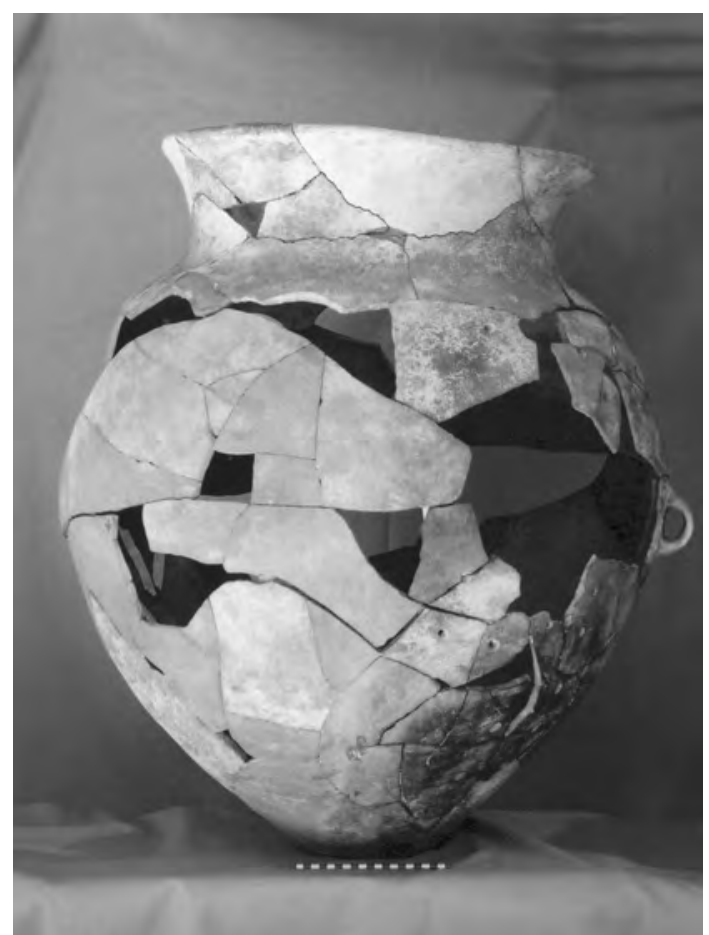

Figura 12. Maqma de base plana proveniente del Cuarto 3. Nótese que esta vasija ya había sido restaurada inicialmente.

fueron halladas en los mismos contextos. Recordando que dichas vasijas decoradas ya habían sido previamente restauradas, no cabe duda que sus funciones originales ya habían sido modificadas. Es decir, éstas probablemente sirvieron como recipientes de granos u otros productos similares, no obstante que sus funciones originales debieron ser otras.

En el curso de las excavaciones y el posterior análisis se observaron muchos otros fragmentos de cerámica con orificios similares a las presentes en las vasijas restauradas. Esto sugiere que en Marayniyoq, las vasijas fragmentadas no fueron desechadas de inmediato; más bien fueron restauradas, no obstante que dicho proceso resultó en la modificación de la inicial función de las vasijas. Esta práctica, desde ya contrasta con la observada en otros sitios Wari, como Conchopata, donde vasijas finamente decoradas fueron intencionalmente sacrificadas (Isbell \& Cook 2002; Ochatoma \& Cabrera 2002). Esta diferencia 
pone en relieve las distintas funciones cumplidas por ambos sitios y por consiguiente las diferencias en el comportamiento de sus residentes. La evidencia de Marayniyoq, a su vez, es una primera instancia para sitios Wari de todo el valle de Ayacucho donde efectivamente se observa el reuso de vasijas rotas. Del mismo modo, a parte de las diferencias en cuanto a forma se refiere, cabe resaltar que entre las vasijas aquí mencionadas existen diferencias en la manufactura y el tratamiento final. Un grupo mayor está compuesto por vasijas de acabado simple, de superficie áspera (generalmente alisados) y sin engobe. Ésta incluye tanto maqmas, qipiris y tinajas, estas vasijas por lo general presentan una base cónica (Figura 13). La superficie externa de dicha base aparece con muchas estrías, producto precisamente de haber estado posicionadas en hoyos, probablemente apoyadas a las paredes. Sus paredes, variando de acuerdo al tamaño, pueden ser bas-

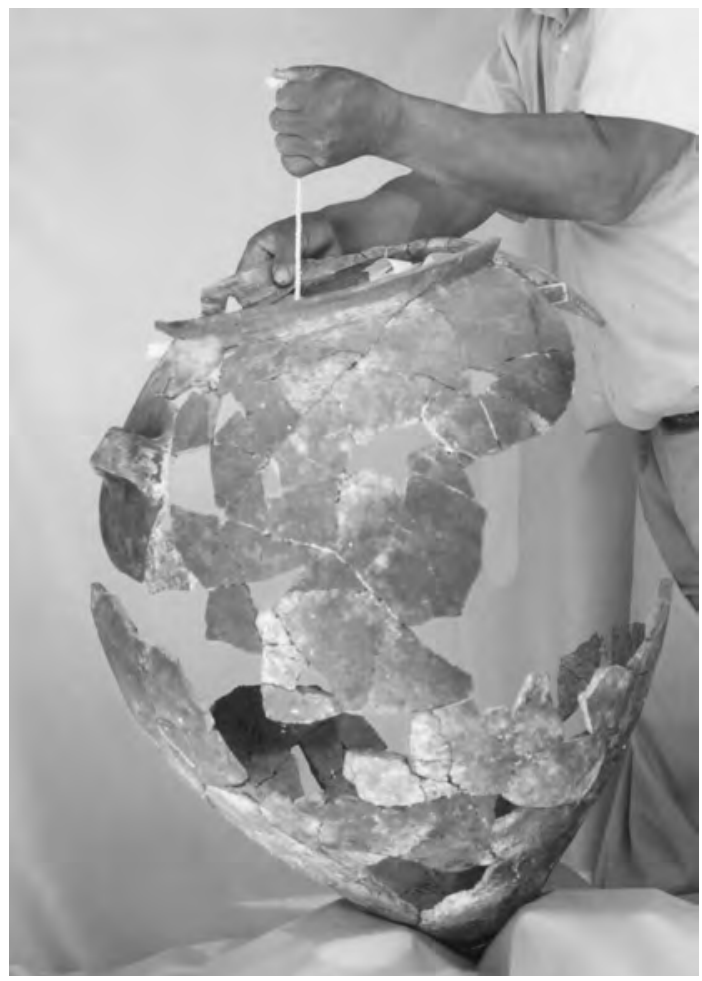

Figura 13. Maqma de base cónica y no decorada proveniente del Ambiente 1. tante gruesas $(2.20 \mathrm{~cm})$ o bien delgados $(0.80$ $\mathrm{cm})$. En la pasta, que por lo general es gris o negra, es visible la presencia de desgrasantes, generalmente arena, además de mica y feldespato.

Por otro lado, algunas vasijas, como los qipiris, sí recibieron mejor tratamiento. A diferencia de las anteriores, éstas últimas siempre presentan una base plana (Figura 10). En un caso se pudo notar que la manufactura fue mediante la técnica del anillado, luego alisado, sobre la cual se aplicó un fino engobe. Sobre dicha superficie, finalmente, se plasmó una variedad de diseños. Para otros qipiris, al igual que para otras vasijas, no se logró determinar la técnica de manufactura, aunque parecen haber sido mediante el paleteado. Unos terceros, además del engobe y pintado, también fueron moldeados, por lo menos en su parte superior. Estos consisten de representaciones antropomorfas, generalmente identificadas como "caras gollete" (Figura 14). La pasta de las vasijas

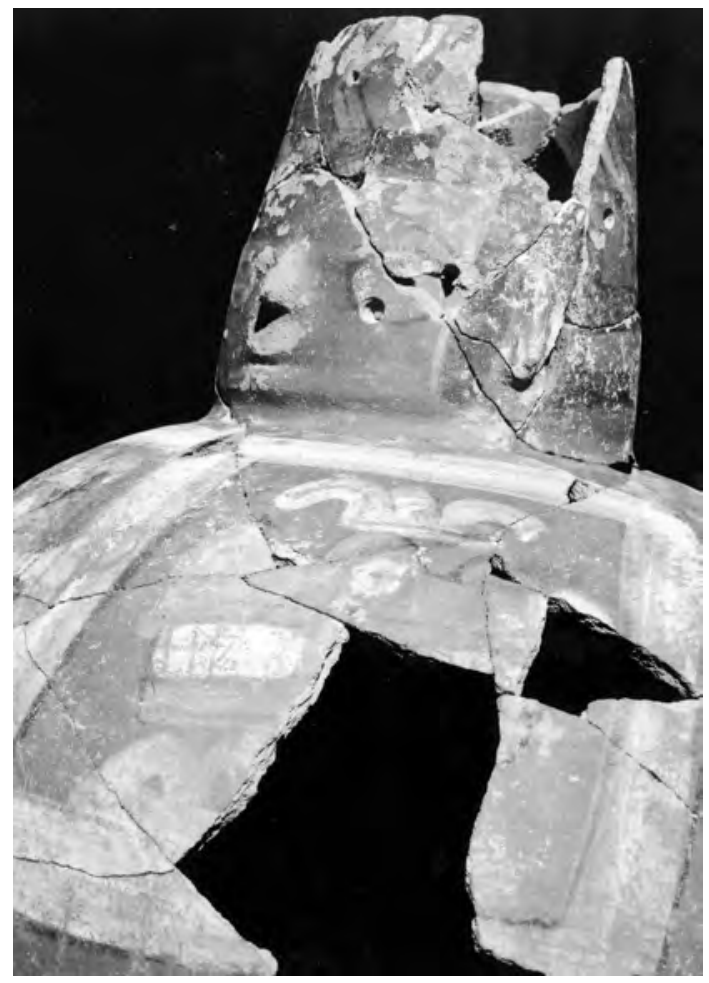

Figura 14. Cara gollete proveniente del Recinto A y que ya había sido restaurada en el pasado. 
decoradas es también distinta en comparación a las anteriores; ésta es de color naranja y los desgrasantes no siempre son visibles. Todo esto sugiere que hubo un mejor cuidado en la producción de vasijas específicas, como fueron aquellas expuestas en reuniones públicas. Estas son las vasijas que presentan una base plana.

Obviamente, las vasijas decoradas fueron producidas para ser movilizadas en cualquier dirección. Como tales, dichas vasijas estaban en contacto con la audiencia (Figura 15). Esta diferencia de haber sido vistos hizo que determinadas vasijas hayan sido no sólo mejor elaboradas y decoradas, sino también provistas de una base plana. El hecho que las vasijas encontradas en sitios como Conchopata son generalmente finamente decoradas (Isbell \& Cook 1987, 2002; Ochatoma \& Cabrera 2002) deja evidente que las vasijas fueron manufacturas distintamente de acuerdo a la función a la que fueron destinadas y sobre todo al lugar y contexto en la que fueron utilizadas. Desde luego, las provenientes de Marayniyoq no son comparables, en cuanto a decoración se refiere a las recuperadas en Conchopata.

Este tratamiento desigual de las vasijas de cerámica de Marayniyoq, al parecer, estaba fuertemente acondicionado por la función a la que estaban destinadas. En efecto, aquellas destinadas a cumplir funciones de simples recipientes y graneros, y como tales a permanecer al interior de las estructuras, recibieron menor cuidado. En contraste, vasijas destinadas a ser utilizadas en espacios abiertos y como tales expuestas públicamente fueron mejor elaboradas, decoradas y dotadas de una base plana. Estas formas, desde ya no son del todo novedosas, en tanto que Anders (1989:11) y Schreiber (1992:213) han reportado su presencia en contextos Wari.

Está por demás anotar que la cerámica Wari ha sido objeto de varios estudios de diferente índole (Menzel 1964; Cook 1987; Knoblock 1991); sin embargo, y con notables excepciones (Anders 1989; Schreiber 1992), vasijas utilitarias que por lo común carecen del llamativo arte

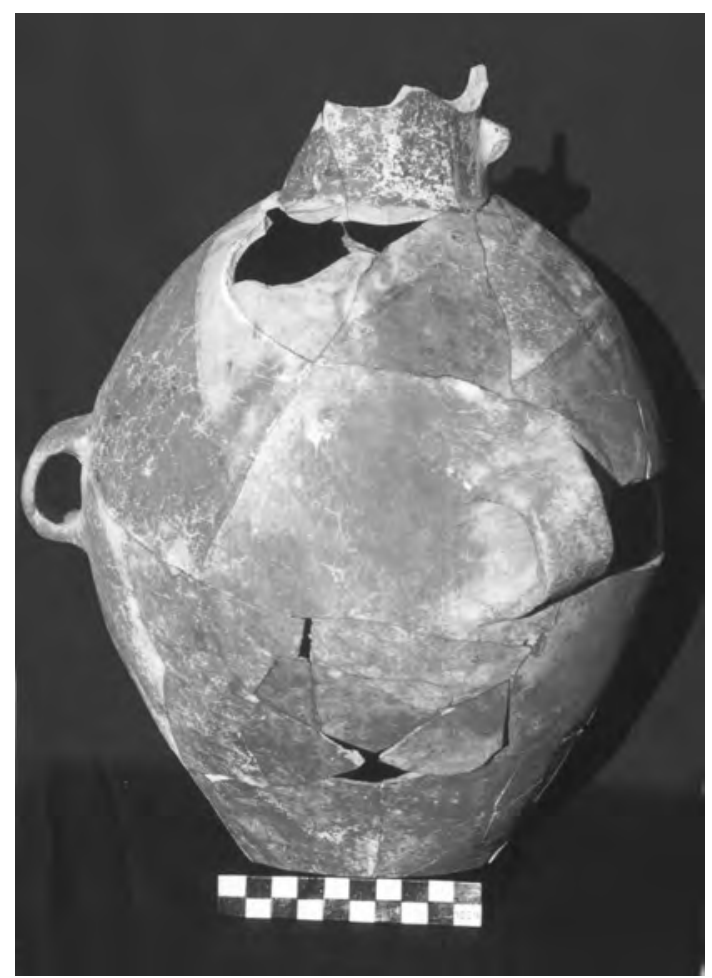

Figura 15. Qipiri pequeño proveniente del Ambiente 1.

Wari han sido dejadas de lado. Como resultado, las variedades de cerámica Wari utilizadas en las actividades cotidianas y fuera de contextos de la élite, siguen aún pobremente estudiadas. Precisamente dichas vasijas poco llamativas desde el punto de vista artístico, fueron las empleadas en actividades importantes como la preparación de la chicha. Por cuanto éstas no han sido objetos de estudios sistemáticos (estilístico o tipológico), incluso la ubicación temporal de dichas vasijas permanece desconocida. Los trabajos en Marayniyoq, por lo tanto, al ubicar piezas decoradas directamente asociadas a piezas llanas o sin decoración (ver Figura 3) pone en claro que además de la fina cerámica, una buena proporción de la cerámica manufacturada y utilizada por la población Wari incluyó a varias formas nodecoradas.

Finalmente, es importante anotar que solo una sección de los qipiris fueron decorados. Dicha 
Figura 16.

Ilustración de

cómo se transporta

un qipiri $y$ de

cómo las vasijas

encontradas en

Marayniyoq

fueron decoradas.

Nótese la dirección

del gollete en

relación a la

cabeza de la

persona que la

transporta.

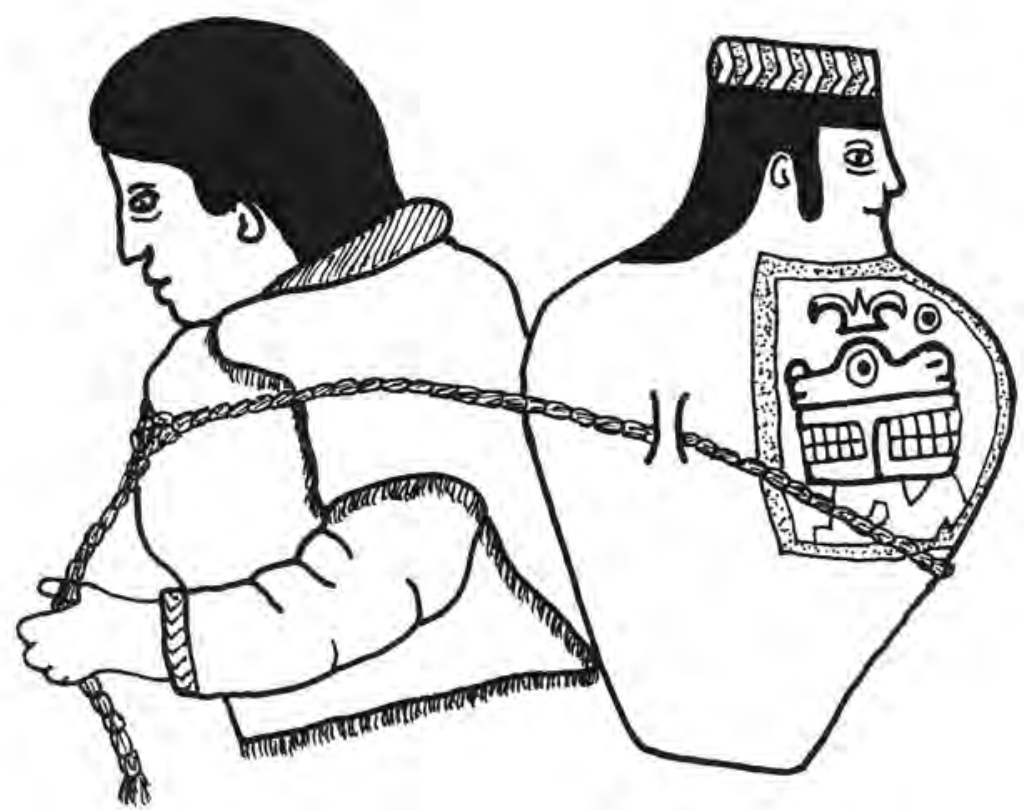

sección viene a ser la parte superior del cuerpo de la vasija; de esta, la sección que da hacia la espalda de la persona que lo carga nunca fue decorada. La representación, más bien se limita hacia el sector expuesto mientras la vasija es transportada en la espalda de un individuo (ver Figura 16).

Esa forma de decorar a las vasijas transportables, es decir a los qipiris, no parece que fue simplemente un accidente y menos una mera coincidencia; por el contrario, la forma cómo se plasmaron los diseños y la posición de la cara de las vasijas en relación a las asas parecen haber sido cuidadosamente ejecutadas para, de ese modo, hacer que la orientación sea opuesta al individuo que la transportó.

Al realizar ese procedimiento, se garantizó la exposición de la vasija, permitiendo así que el personaje representado en la vasija pueda no sólo "visualizar" su entorno, sino también sea visto y de este modo establecer un "contacto" con la comunidad en general. Si estas vasijas sirvieron en efecto para transportar la chicha, tal como se sostiene a lo largo de este trabajo, el "contacto" con la comunidad debió haber tenido mayor sig- nificado, donde posiblemente las vasijas cara gollete fueron identificadas como los proveedores de la chicha. Al hacer esto, por último, el Estado habría sido la entidad beneficiada en tanto que las vasijas eran precisamente los representantes de dicha organización.

En resumen, de la información arriba discutida, especialmente de la presentada en el Cuadro 3 , se desprende que alrededor del $89 \%$ de las vasijas presentes en Marayniyoq fueron destinadas al almacenamiento y la transportación de bebidas. Aunque muchas de dichas vasijas hayan cumplido dichas funciones, la presencia de vasijas restauradas y obviamente reutilizadas tiende a sugerir que un buen porcentaje de las vasijas halladas en Marayniyoq sirvieron para el almacenamiento de granos como el maíz o productos similares. Dicho escenario se hace evidente al considerar los otros artefactos hallados en Marayniyoq, siempre en los mismos contextos de donde provienen las vasijas de cerámica hasta aquí discutidas. Dicha evidencia se discute a continuación; en otro trabajo se prestará mayor atención a los elementos aquí discutidos. 


\section{Los instrumentos de moler}

Sin lugar a equivocaciones, uno de los mejores descubrimientos de los trabajos efectuados en Marayniyoq son los instrumentos de moler, compuesto de batanes (maray) y sus respectivas moliendas (tunay) o partes activas. Los batanes serán tratados en mayor detalle en otro trabajo, razón por la cual lo que sigue es sólo una referencia breve. Los batanes consisten de piedras trabajadas, algunas de las cuales son verdaderos bloques, todas colocadas una al lado de otra. Este es el aspecto más sobresaliente que viene diferenciando al sitio de Marayniyoq de otros sitios Wari del valle de Ayacucho (Valdez 2002a, 2002b). En efecto, y con la excepción del mismo centro urbano de Wari, donde piedras trabajadas han sido expuestas en diferentes contextos (Benavides 1991; Isbell, Brewster-Wray \& Spickard 1991), hallazgos parecidos a los de en Marayniyoq no han sido descubiertos en otros sitios. Este es el caso, por ejemplo, de los recientes trabajos efectuados en Conchopata (Isbell 2001; Ochatoma \& Cabrera 2001a). En Aqo Wayqo tampoco hay piedras trabajadas (Ochatoma \& Cabrera 2001b); por lo tanto, en virtud de dichos hallazgos, Marayniyoq es un sitio Wari con características únicas en todo el valle de Ayacucho, y tal vez en toda la sierra central.

El caso de los instrumentos de moler será discutido en mayor detalle en otro trabajo; por lo tanto, aquí sólo se hará una referencia general. Las piedras trabajadas tienen tamaños diferentes, aunque sus formas tienden a ser relativamente homogéneas. Las piedras expuestas durante la primera temporada de trabajo de campo, las mismas que están ubicadas al lado norte (ver Figura 2), en su mayoría consisten de grandes bloques, por lo general de forma rectangular. Dichos bloques, además de otras más pequeñas, habían sido establecidos en forma alineada y en dos grupos, uno con una orientación norte-sur y otro con una orientación este-oeste. En la parte intermedia se habían colocado piedras trabajadas más pequeñas. En conjunto, todas fueron colocadas sobre un relleno que contenía abundante canti- dad de fragmentos de cerámica, generalmente en el estilo Wamanga. Un piso compacto había sido construido adyacente a los bloques de piedra, mientras que un muro largo con una orientación de este a oeste pasaba por su lado Sur.

Por su parte, las piedras trabajadas encontradas durante las dos temporadas más recientes son de tamaños más pequeños que las anteriores, y por lo general son de formas cuadradas y rectangulares. Se encuentran al lado sur con relación al grupo de las grandes piedras. En total, dichas piedras forman tres grupos y cada uno de estos grupos, puesto en conjunto, forman un "recinto" en forma de U (Recintos, A, B y Cen Figura 2). En la parte central de dichos posibles recintos aparece un piso compacto en buen estado de conservación. Tal como ya se anotó, en dos casos, sobre dicho piso de halló una gran acumulación de cerámica fragmentada.

Todas las piedras trabajadas, incluidos los grandes bloques del lado norte, fueron muestras en paralelo a muros previamente construidos. Las piedras del lado sur en particular aparecen al interior de muros, dando la impresión de haber sido inicialmente utilizados a modo de banquetas. Por su parte, las piedras grandes del lado norte parecen haber sido instaladas al lado exterior de los muros. De acuerdo al análisis hecho por Octavian Catuneann, la roca utilizada como batanes viene a ser una roca arenisca. Por su parte, Andrés Portugal Paz ha determinado que la textura de la roca es clástica de grano fino, de origen sedimentario y que se encuentra expuesta en la parte superior media del Cerro Allkowillka, ubicado a corta distancia al sur de Marayniyoq. Aunque no se llegó a ubicar el lugar exacto de donde se extrajeron dichos bloques, queda evidente que los materiales utilizados en la construcción de Marayniyoq fueron de origen local.

Desde el hallazgo de las primeras piedras trabajadas con depresiones en 1999 (Valdez 2002a: Fig. 6), el principal foco de las investigaciones en Marayniyoq fue definir la función de dichas piedras. Dentro de la disciplina arqueológica, la asociación de los artefactos constituye el punto más 
crítico de todo análisis e interpretación de las muestras arqueológicas. Sabemos, desde luego, que los artefactos arqueológicos rara vez se encuentran en los mismos lugares donde fueron utilizados por última vez. Esto como resultado de los procesos tafonómicos. Para el caso de Marayniyoq, tampoco se ha esperado que todos los artefactos recuperados durante las excavaciones fuesen encontrados en los mismos lugares donde fueron utilizados por última vez. La interpretación de los materiales culturales descubiertos en Marayniyoq está basada en la asociación funcional de todos los artefactos (Valdez, et al., 2000: Fig. 14) y se complementa con el uso de la analogía etnográfica (Valdez 2002b, 2003).

Un buen número de las piedras expuestas en Marayniyoq presentan depresiones de forma ovoide (Figura 17), mientras que otras piedras tienen la superficie pulida. Estos dos elementos no parecen haber sido intencionalmente hechos, sino deben ser producto de alguna actividad efec- tuada sobre dichas piedras. Afortunadamente, además de las mismas piedras trabajadas, las excavaciones pusieron al descubierto artefactos adicionales, los mismos que son de suma importancia para comprender la función de las piedras en mención y del mismo sitio en particular. En efecto, durante la primera temporada de trabajos se hallaron, sobre las mismas piedras trabajadas, cuatro piedras de forma de un pallar, localmente identificables como tunay (ver Valdez, et al. 2000). Durante las excavaciones más recientes efectuadas en el sitio, nuevos artefactos similares, fueron nuevamente puestos al descubierto y siempre en asociación a las piedras con depresiones (Figura 18). Dichas piedras, excepto una, tienen por lo general uno de sus lados bien pulido, mientras que la forma de tales piedras es bastante similar a las depresiones presentes en las piedras trabajadas.

De fuentes etnográficas se conoce que piedras similares, conocidas como tunay, siguen sien-

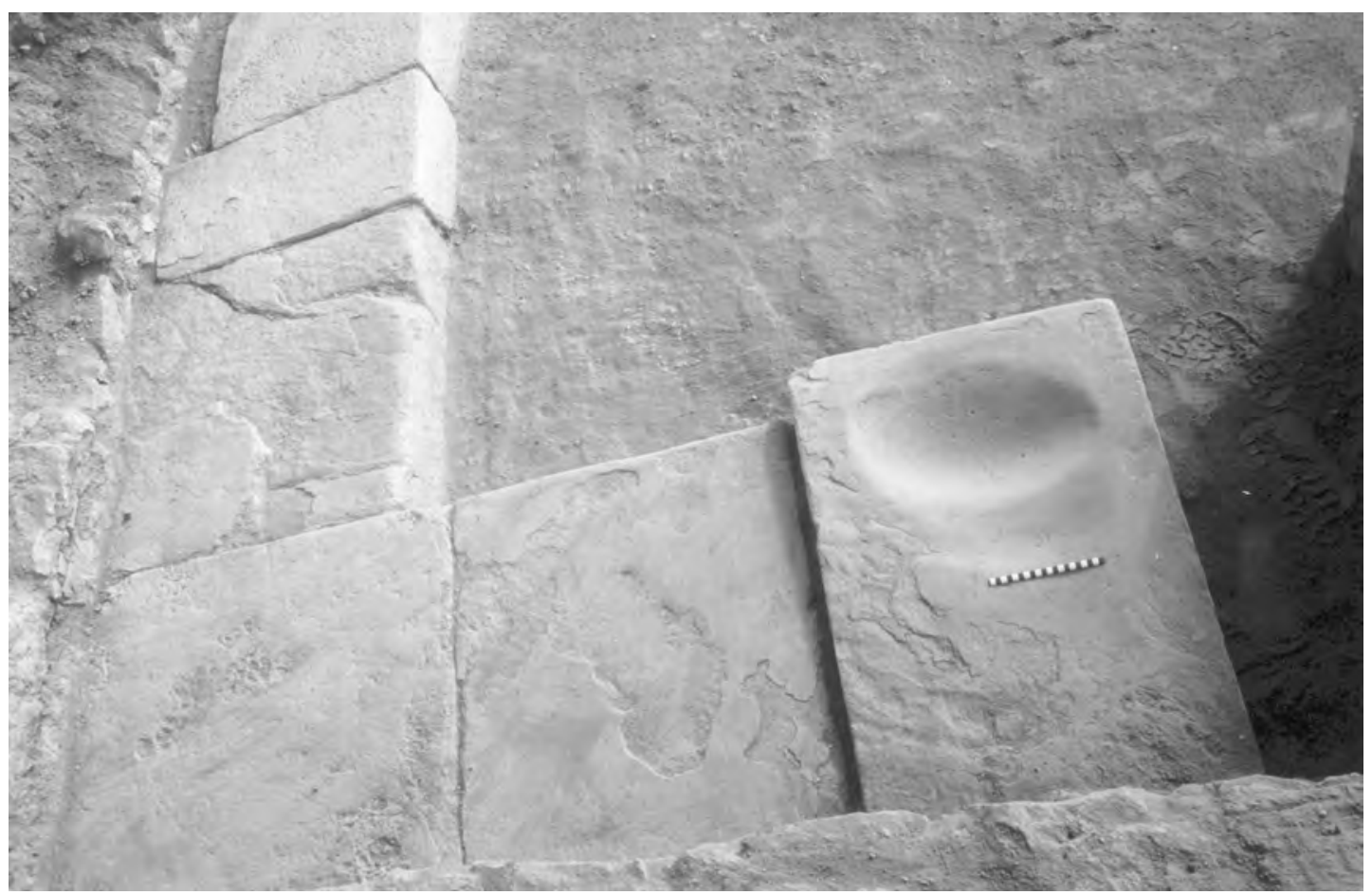

Figura 17. Batán con depresión pronunciada hallada en el Recinto B. 


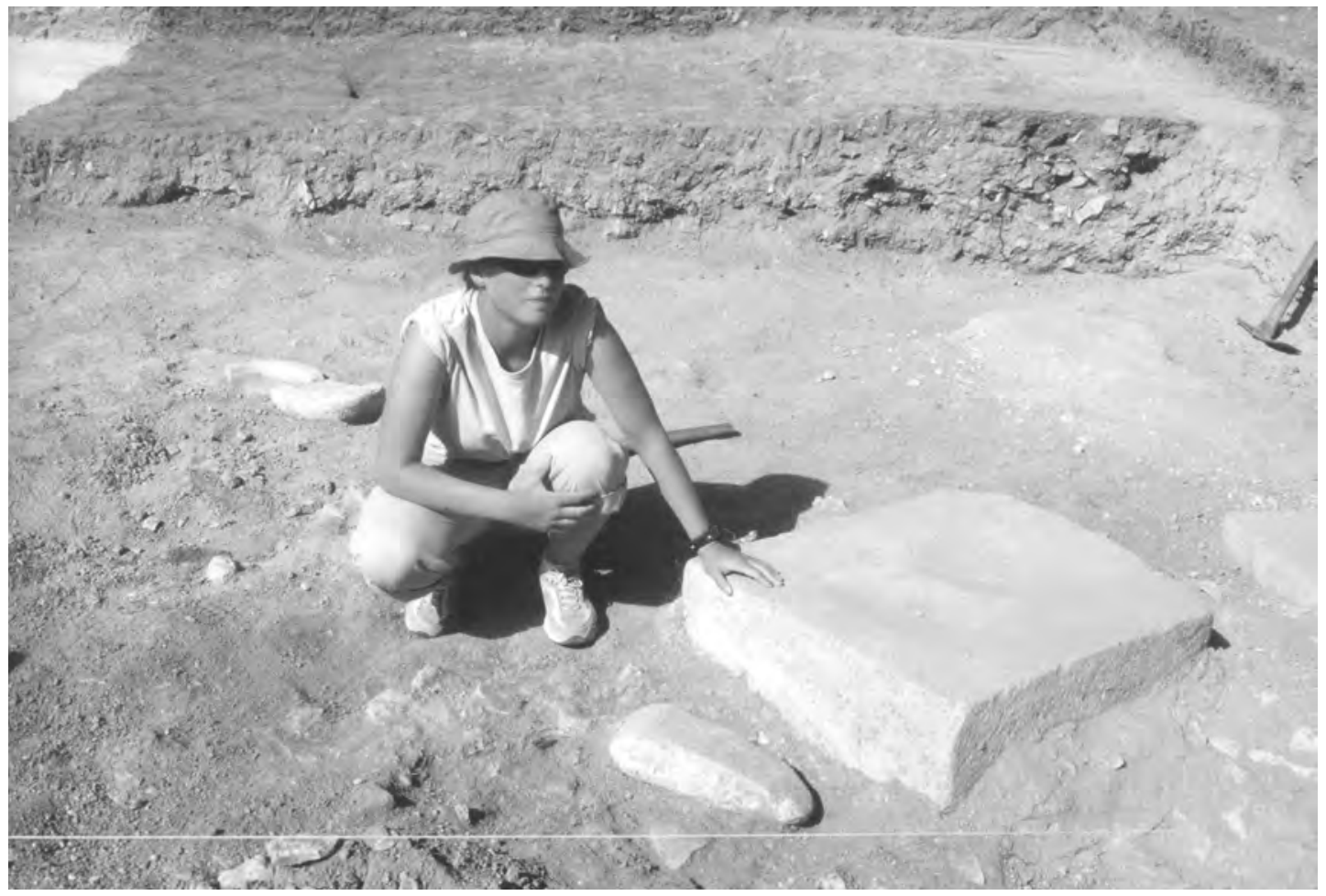

Figura 18. Una asociación de un batán y una molienda en el Recinto A.

do utilizadas en el valle de Ayacucho y alrededores como las partes activas de los batanes. En base a esta analogía, existe poca duda que dichas piedras sirvieron para moler. En otras palabras, las referidas piedras fueron las partes activas, mientras que la parte pasiva fue constituida por las piedras trabajadas que presentan depresiones. Considerando que ambos elementos ocurren asociados y que como se conoce son funcionalmente complementarios, Marayniyoq parece ser en efecto un centro asociado con el procesamiento de granos. Nuevamente, la asociación de dichos artefactos es de particular interés e importancia para poder comprender la función de los bloques de piedra, así como del mismo sitio de Marayniyoq.

Tal como David (1998) y Adams (1999) discuten, una de las principales características de los batanes son las depresiones de variada profundidad. Las piedras de Marayniyoq no son una excepción al respecto (Valdez, et al., 2000:557).
Una característica adicional son las superficies planas y pulidas ubicadas a una distancia alcanzable por el brazo de una persona, que también están presentes en las piedras trabajadas de Marayniyoq. Tal como ya se anotó, las depresiones aparecen sólo cerca a uno de los extremos de la superficie de la piedra, mientras que al extremo opuesto por lo general aparece una pequeña cresta. Importante es anotar, además, que el largo de las depresiones va paralela al borde las piedras (Valdez 2002a:76); esta es una instancia que indica que la molienda fue utilizado en el mismo sentido como en la actualidad las moliendas son utilizados en el valle de Ayacucho. Es decir, las moliendas son movidas sobre el batán con ambas manos "de lado en lado" (de izquierda a derecha) repetidamente; este tipo de movimiento resulta en depresiones como las observadas en Marayniyoq. Sólo en un caso se observó una forma distinta de depresión que resultaría del manipuleo de la parte activa en un sentido opues- 
to al anterior; es decir de "acá para allá" (o de atrás para adelante). Este tipo de movimiento, parcialmente desconocido en la región Andina, es ampliamente practicado en México, el Suroeste norteamericano (Adams 1999) y Nigeria (David 1998). En este tipo de movimiento, la parte activa es manipulada por lo general con una sola mano.

La presencia de las depresiones en serie y siempre a un extremo de los grandes bloques de piedra sugiere también que varias personas, tal vez de manera simultánea, fueron quienes pusieron en funcionamiento a esta importante facilidad (Valdez, et al., 2000:559). Como tal, el procesamiento de granos debió haber sido una actividad social. Este personal bien pudo haber sido un grupo de especialistas, como las aqllas (y/o mamaconas) del Estado Inka, o personal tributario. Por cuanto en las inmediaciones de las piedras trabajadas y sobre el piso compacto se han encontrado algunos instrumentos de hilar, representados en forma de piruros y considerando que la actividad de hilar en el contexto andino fue tradicionalmente asociado con la mujer (Gero 1990:54; Murra 1983:107; Rowe 1946:241), existe la posibilidad que fueron las mujeres quienes pusieron en funcionamiento aquella facilidad. Esta observación se corrobora por el hecho que tradicionalmente el uso del batán también está asociado con la mujer (Hastorf 1991:134). Por lo tanto, existe la probabilidad que la actividad desarrollada en Marayniyoq fue asociada con el trabajo de la mujer.

La presencia de las depresiones sugiere además que la actividad desarrollada en Marayniyoq no sólo fue intensa, sino probablemente desarrollado por un tiempo lo suficientemente prolongado. Tal como David (1998:31) nos recuerda, por ejemplo, las depresiones no son intencionalmente hechas; más bien, éstas vienen a ser el resultado de la actividad de moler. Mientras que en Marayniyoq tenemos piedras con superficies pulidas y otras con depresiones, queda claro que la primera evidencia de la actividad de moler son definitivamente las superficies pulidas. En conse- cuencia, no cabe duda que las depresiones observadas en las piedras trabajadas de Marayniyoq atestiguan la intensa y probable prolongada actividad efectuada en el lugar. Desde luego, el tipo de las piedras y los productos procesados sobre éstas deben tener directas implicancias en la formación de las depresiones (Valdez 2003).

La interrogante que surge es qué producto fue procesado en Marayniyoq. Lamentablemente, ninguna muestra de semilla fue recuperada durante los trabajos de campo, haciendo que este aspecto de Marayniyoq permanecerá especulativo. En otros trabajos (Valdez 2002a; Valdez, et al. 2001) ya se ha sugerido que dicho producto posiblemente fue el maíz o en su efecto la qora, maíz procesado para la elaboración de la chicha. Se debe recordar que incluso en sitios Inka, como Huánuco Pampa, Morris (1979) no ha logrado ubicar semillas de maíz o en su efecto de la qora, maíz procesado exclusivamente para la preparación de la chicha (Moore 1989). En consecuencia, solo contamos son evidencias indirectas que de algún modo apuntan hacia el procesamiento de algún producto, el mismo que bien pudo haber sidolaqora.

Las vasijas utilizables en el almacenamiento de granos, incluidas aquellas que fueron restauradas paraluego ser reutilizadas, muy probablemente funcionaron en asociación a la actividad desarrollada sobre los batanes. Estos detalles se discuten a mayor profundidad en la parte final del trabajo. Antes de eso, se hace una referencia a la ubicación temporal del sitio en estudio.

\section{La ubicación temporal de Marayniyoq}

Varias muestras de carbón fueron obtenidas durante los trabajos de excavación efectuados en Marayniyoq. De todas, un total de siete muestras fueron sometidas al IsoTrace Radiocarbon Laboratory de la University of Toronto, en Canadá. La proveniencia de cada muestra está ilustrada en la Figura 2 con una X, mientras que la Figura 19 ilustra dichos resultados. Los resultados han sido calibrados por el mismo laboratorio. Además de la fecha no calibrada (AP), las fechas 


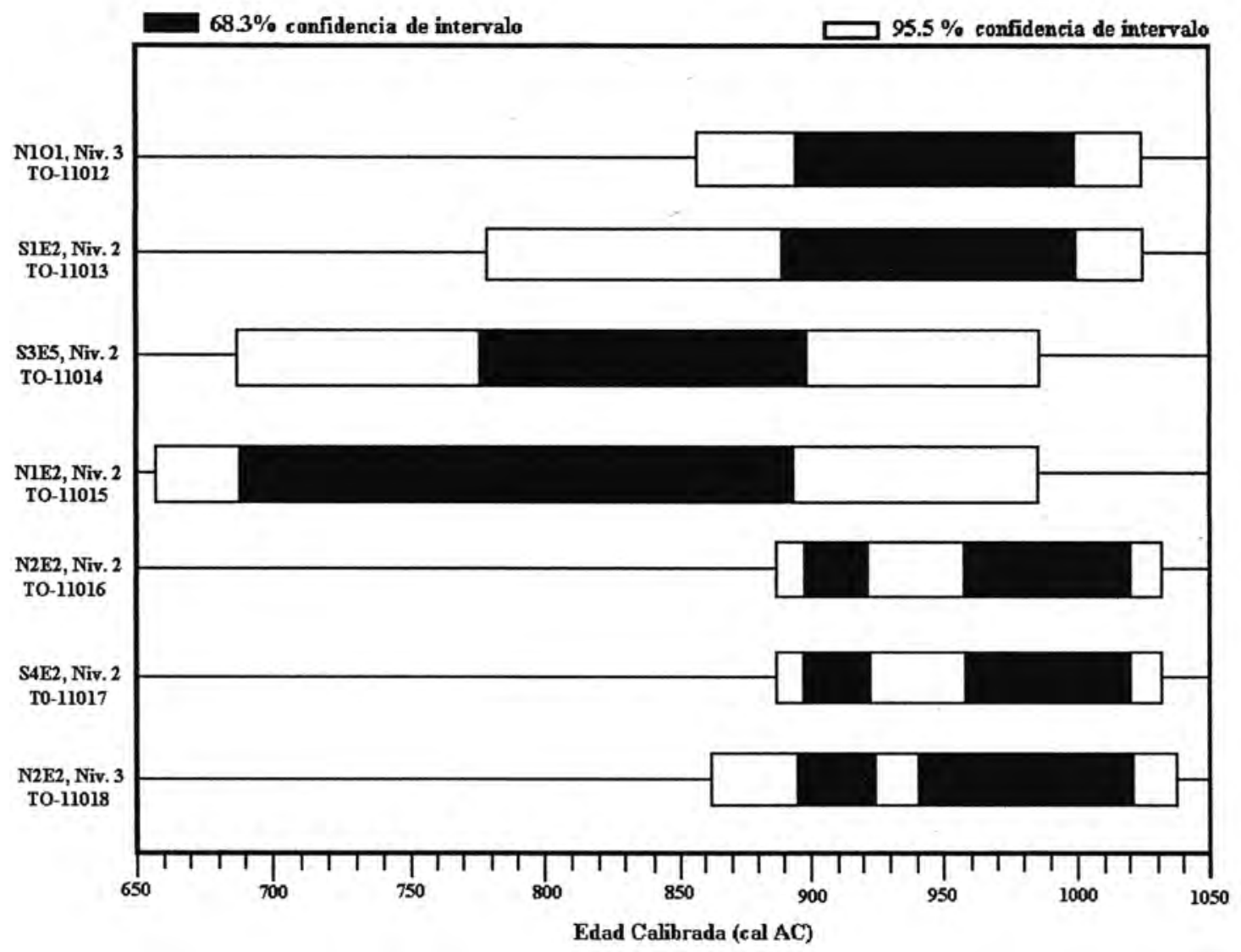

Figura 19. Fechados de carbón obtenidos para el sitio de Marayniyoq. La primera nomenclatura indica la proveniencia de cada muestra, mientras que la segunda nomenclatura es la que corresponde al Laboratorio de Accelerator Mass Spectrometry de la Universidad de Toronto.

fueron calibradas al 68\% (una sigma) y el 95\% (dos sigmas) de confidencia de intervalo. En todos los casos, los resultados fueron redondeados al más próximo múltiplo de 5 años. De acuerdo a estos resultados, el piso asociado a los batanes, y desde luego los batanes, fue el escenario de una intensa actividad entre los años $680-700$ d.C. y 1020 - 1040 d.C. Una muestra (TO11015) de carbón proveniente de las inmediaciones de los grandes bloques de piedra con depresiones, aunque del lado Sur del muro, sugiere una mayor actividad en el lugar alrededor del año 750
d.C. Tal como demuestran las dos últimas muestras (TO-11017 y TO-11018), nuevas construcciones habrían iniciado a ser establecidas en el sitio alrededor de los años 870 y 900 d.C. Puesto que las nuevas construcciones sellaron parte de las instalaciones previas, no cabe duda que la función del sitio cambió substancialmente alrededor de esos años. Entonces, Marayniyoq se habría convertido en un pequeño y modesto asentamiento rural. Su población, sin embargo, continuó utilizando cerámica decorado en el estilo Wamanga. 
Cuadro 4. Fechados de Carbón obtenidos para el sitio de Marayniyoq.

\begin{tabular}{|c|c|c|c|c|c|}
\hline Muestra & $\begin{array}{l}\text { Peso } \\
(\mathrm{Mg})\end{array}$ & $\begin{array}{l}\text { Edad } \\
\text { calibrada }\end{array}$ & $\begin{array}{l}\text { 68.3\% c.i. } \\
\text { (1 sigma) }\end{array}$ & $\begin{array}{l}95.5 \% \text { c.i. } \\
\text { (2 sigmas) }\end{array}$ & $\begin{array}{l}\text { Edad antes del } \\
\text { presente (AP) }\end{array}$ \\
\hline 1. N1O1-3 & 570 & $900 \mathrm{cal}$ DC & 890995 DC & $8551020 \mathrm{DC}$ & $1100 \pm 50 \mathrm{AP}$ \\
\hline 2.S1E2-2 & 597 & 900 cal DC & $885995 \mathrm{DC}$ & $7751020 \mathrm{DC}$ & $1110 \pm 60 \mathrm{AP}$ \\
\hline 3.S3E5-2 & 421 & $780 \mathrm{calDC}$ & $770895 \mathrm{DC}$ & $685980 \mathrm{DC}$ & $1190 \pm 60 \mathrm{AP}$ \\
\hline 4. N1E2-2 & 697 & $775 \mathrm{calDC}$ & $685890 \mathrm{DC}$ & $655980 \mathrm{DC}$ & $1230 \pm 80 \mathrm{AP}$ \\
\hline 5. N2E2-2 & 866 & $905 \mathrm{calDC}$ & $895920 \mathrm{DC}$ & $8851030 \mathrm{DC}$ & $1070 \pm 50 \mathrm{AP}$ \\
\hline 6.S4E2-2 & 375 & $905 \mathrm{calDC}$ & $895920 \mathrm{DC}$ & $8851030 \mathrm{DC}$ & $1070 \pm 50 \mathrm{AP}$ \\
\hline 7.N2E2-3 & 354 & $905 \mathrm{calDC}$ & $895920 \mathrm{DC}$ & $8601035 \mathrm{DC}$ & $1070 \pm 60 \mathrm{AP}$ \\
\hline
\end{tabular}

\section{Discusión y conclusión}

En una publicación bastante conocida por los especialistas, Morris (1979:27) ha manifestado que la evidencia arqueológica con respecto a la producción y consumo de la chicha durante el Tawantinsuyo es "menos directa". Los únicos elementos de juicio con los que contamos son efectivamente, como señala Morris, las vasijas fragmentadas y otros utensilios que fueron utilizados en dicha actividad. Sólo bajo condiciones excepcionales se llega a recuperar los elementos orgánicos, en este caso la qora, el principal producto para la producción de la chicha. Cuando éste es el escenario, uno se pregunta si los especialistas hubiéramos sido hábiles en reconocer la importancia de la chicha en tiempos Inka, en la misma forma como hoy lo sabemos, sin contar con los escritos de los cronistas como Cobo (1956:204). En todo caso, sin los escritos de los cronistas, tal vez hubiera sido difícil, sino imposible, llegar a saber que la ciudad capital Inka era identificado bajo el nombre de Aqamama o madre chicha, por que simplemente no habrían los elementos materiales para que nosotros los especialistas estudiemos y lleguemos a tal identificación. Para el beneficio de los especialistas y de los estudios Inka en particular, afortunadamente contamos con documentos escritos que nos dan a conocer, por ejemplo, que grupos de mujeres conocidas como aqllas, establecidas en cada una de las principales ciudades Inka, eran las encargadas de la producción de la chicha (Pizarro 1965:194). Con la ayuda de dicha información y el hallazgo de los utensilios en la producción de la chicha, Morris (1988:48; Morris \& Thompson 1985) llegó a reconocer que en Huánuco Pampa había un sector ocupado por aqllas y que estaba orientado precisamente a la producción de la chicha.

Para las culturas pre-Inkas no contamos con información escrita, de tal modo que la producción y consumo de la chicha tiene que ser evaluado sola y únicamente en base a las evidencias materiales, que como ya se señaló son menos directas. En tal situación, sin embargo, recurrimos a menudo a la información etnográfica y desde luego al caso Inka (Isbell \& Cook 1987:28) como modelos que ayuden a explicar nuestros hallazgos. Aunque no necesariamente abogamos por una continuidad histórica, existe la posibilidad que mucho de lo practicado y hecho por los Inkas ya fue practicado y hecho con anterioridad. Partiendo de esta premisa, análogos entre lo conocido para los Inkas y algunas evidencias para las culturas que lo antecedieron son consideradas como indicadores de eventos y actividades similares.

La información propiamente arqueológica con respecto a la producción y consumo de la chicha en tiempos Inka no deja de ser limitado, tal información es todavía más frágil para culturas como Wari. Sin embargo, en base a datos indirectos, como el hallazgo de vasijas grandes, los especialistas continuamente han planteado una opinión favorable con respecto a la producción y con- 
sumo de la chicha en tiempos Wari (Anders 1991:191; Isbell, Brewster-Wray \& Spickard 1991:43; Isbell \& Cook 1987:28, 2002:277; Ochatoma \& Cabrera 2002:236; Raymond 1992:22). Muchos de estos especialistas también han sostenido a favor de la chicha de maíz, el cual obviamente implica la qora. Si ponemos el caso de la chicha en un escenario más amplio, como por ejemplo su consumo durante las actividades rituales y la directa participación de la entidad estatal, esto obviamente implica que una masiva cantidad de chicha debió haber sido producida. Esto, a su vez, supone directamente que una cantidad considerable de qora tuvo que ser procesada. Aunque dicho producto pudo haber sido procesado a nivel de cada unidad doméstica, lo más eficiente debió haber sido, y posiblemente lo fue, procesar la qora en un centro específico. Esto especialmente si la organización estatal estuvo involucrada en el procesamiento y distribución de lachicha.

El crítico se preguntará cuáles son las evidencias indirectas para la producción de la chicha en Marayniyoq. Para responder, primero se toma el caso de los batanes y luego de las vasijas. Los instrumentos de moler son parte primordial de toda unidad doméstica, por lo menos desde el punto de vista etnográfico. Por lo tanto, su ocurrencia en sitios arqueológicos no es de extrañar. Sin embargo, cuando dichos instrumentos ocurren en números sorprendentes, tal como sucede en Marayniyoq, obviamente se está al frente de algo que fue diferente de lo doméstico. Y, coincidentemente, Arthur (2002:337, 2003:522) nos recuerda que la presencia de instrumentos de moler fuera de lo normal, desde luego en asociación a otros elementos de juicio, es un indicador de la producción de la chicha. O en su efecto, la presencia conjunta de varios batanes en un sitio particular indudablemente sugiere la existencia de cierto énfasis en moler productos específicos. Entretanto, es oportuno recordar que Cobo (1956:243) describe sucintamente el empleo del batán y la molienda en el procesamiento de la chicha, hecho que D'Altroy (2002:201) ratifica. Tal como se discutió en otro trabajo (Valdez 2002a), la qora necesita ser triturada o molida para la preparación de la chicha. Por lo tanto, la presencia considerable de batanes y sus respectivas partes activas en Marayniyoq indica con suma claridad que la actividad de moler efectuada en el sitio fue superior de lo efectuado a nivel doméstico. A su vez, las depresiones que aparecen en los batanes dejan sin duda que dicha actividad no sólo fue intensa, sino al parecer prolongada. Y, dicha intensidad sólo pudo haberse dado con la producción de la chicha, considerando nuevamente que dicha producción requiere de grandes cantidades de qora molida.

En segundo lugar, la morfología de las vasijas es otro importante indicador del uso de la chicha en el pasado (Arthur 2003:522). En particular, vasijas de gran tamaño tienen una fuerte conexión con la producción de la chicha. Efectivamente, la evidencia etnográfica enseña que vasijas de las formas que predominan en Marayniyoq, como maqmas y tinajas, tienen una conexión con el procesamiento de la chicha. Para el caso Wari, la función de las vasijas grandes continuamente se ha asociado con la chicha (Isbell \& Cook 1987, 2002; Ochatoma \& Cabrera 2001a, 2002). De acuerdo a Arthur (2002:339), una información adicional que indica la producción de bebidas fermentadas es la presencia de erosiones en la superficie interna de las vasijas utilizadas en dicho proceso. Aunque Arthur (2002) no discute el caso andino y menos el caso particular del maíz, es de suma importancia la presencia de tales erosiones en la superficie interna de un qipiri decorado. Dicha erosión, aunque está por confirmarse, podría ser una evidencia tangible de la producción de la chicha en Marayniyoq.

Mientras queda poca duda que un buen número de las vasijas presentes en Marayniyoq sirvieron en la producción y transportación de la chicha, cabe enfatizar que algunas de las vasijas habían sido previamente restauradas (Figura 20). Tales vasijas obviamente no pudieron haber sido recipientes de bebidas, aunque originalmente muy bien debieron haber cumplido dicha 


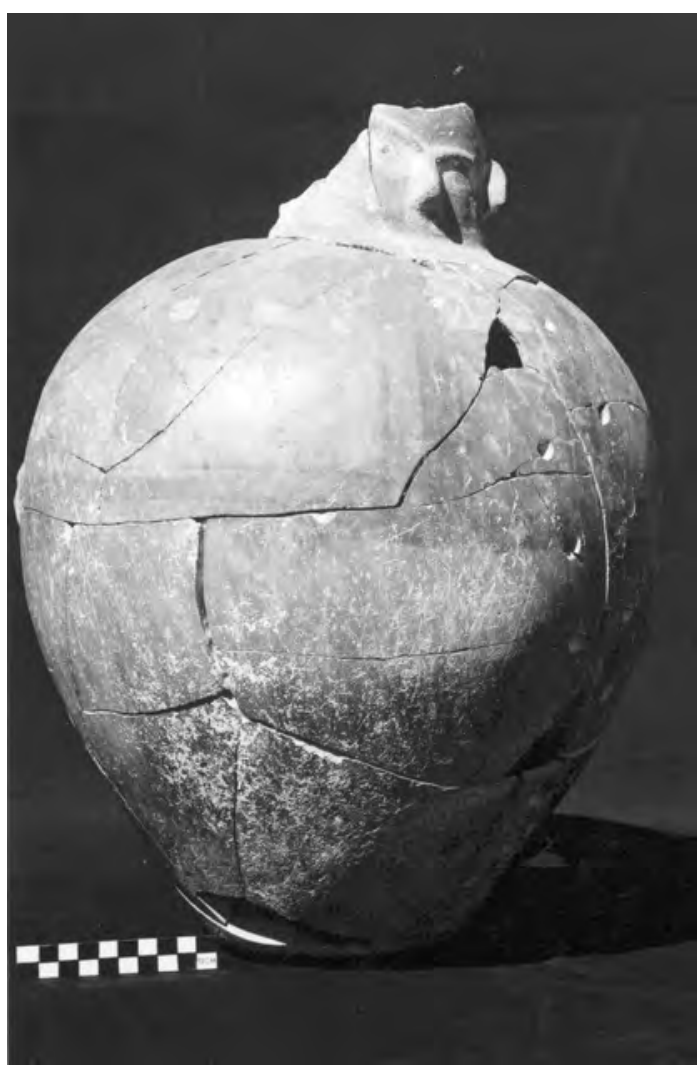

Figura 20. Qipiri mediano de base plana proveniente del Recinto A. Observe el gollete y los agujeros producidos para su inicial restauración.

función. Más bien, dichas vasijas debieron haber sido los recipientes de productos secos como pudo haber sido alguna variedad de granos o en su efecto la misma qora. La ocurrencia de las vasijas, especialmente qipiris, cerca a los batanes sugiere precisamente que dichos recipientes, posiblemente conteniendo la qora, estaban al alcance de las personas que procesaron el referido producto en los batanes. Una posibilidad adicional es que la qora molida fue temporalmente depositada en tales vasijas, para luego ser transportada a los centros donde la chicha fue preparada. Si bien la chicha parece que fue procesada y consumida en el mismo sitio de Marayniyoq, ésta posiblemente fue solo para el consumo local, tal vez del personal que puso en operación a esta importante facilidad. La chicha consumida en sitios como Azángaro, Wari y Conchopata probablemente fue localmente producida, aunque la materia prima, es decir la qora, seguramente fue procesada en Marayniyoq. La ausencia de vasijas grandes aptas para el hervido de la chicha, es decir mankas grandes en Marayniyoq, sugieren en esta dirección.

En base a toda esta observación, se puede sostener que gran parte del área excavada de Marayniyoq fue orientada al procesamiento de granos, tal como sugiere la presencia de batanes en varios lugares. El espacio identificado como Ambiente 1 parece haber sido un lugar donde se guardaron vasijas conteniendo chicha que fue distribuida a los trabajadores que pusieron en funcionamiento el referido establecimiento. La presencia de vasijas identificables como maqmas y qipiris no decoradas, además de un kero decorado y una vasija apta para servir la bebida, coadyuva en dicha dirección. Por su parte, el pasadizo 1 posiblemente fue un lugar de almacenamiento donde productos por procesar o ya procesados fueron temporalmente guardados. La presencia de una vasija inicialmente restaurada así lo sugiere. El cuarto 3 también debió haber cumplido una función parecida. El Recinto A pudo también haber cumplido una función similar al del pasadizo 1 , aunque parece que algunas vasijas ahí recuperadas bien pudieron haber servido para guardar la chicha. El pasadizo 2 parece que fue un lugar donde habrían estado varias vasijas establecidas al lado del muro del lado sur. Tal como indica Meyerson (1990:49), vasijas utilizadas para la fermentación de la chicha generalmente son establecidas cerca a las paredes para asegurar la estabilidad de las mismas. En consecuencia, dicho espacio, además de servir como acceso hacia el Recinto A, debió haber sido un lugar donde se fermentóla chicha para consumo local. El resto de los ambientes parecen haber cumplido diversas funciones, las mismas que debieron incluir el almacenamiento de granos, chicha, y desde luego el mismo procesamiento de productos comola qora.

Sien efecto Wari constituyó un Estado (Lumbreras 1980; Schreiber 1992) y que durante su existencia se llegó a edificar, por ejemplo, centros administrativos (Williams \& Isla 2002; Williams, Isla \& Nash 2001; Glowacki \& McEwan 2001), 
caminos (Schreiber 1991), canales de irrigación y terrazas agrícolas (Schreiber 1992:262), el personal encargado de todas estas tareas, incluyendo la cosecha y almacenamiento de los productos, debió haber sido inmensa. Del mismo modo, y como en los tiempos Inka (ver Cobo 1956:194), el mismo ejército que habría jugado un rol de mucha importancia en la expansión Wari, también debió haber sido numerosa. Todo este personal, sean especialistas o trabajadores rotativos, posiblemente fueron proveídos de comida, además de coca y chicha. Y, si la organización política Wari fue similar al del Estado Inka, donde todo acto público y ritual involucró el consumo de la chicha (ver Allen 1988; Morris 1979), no se puede descartar que su importancia tal vez fue institucionalizada por el aparato administrativo Wari, muchos años antes de la emergencia del Estado Inka.

De este modo, la presencia de un centro de procesamiento de granos como Marayniyoq y donde probablemente se procesó la qora no está fuera de contexto. Más bien, Marayniyoq resalta la importancia de la chicha, la misma que parece haber sido producida y redistribuida por el Estado en un signo de reciprocidad. En otras palabras, la provisión de la chicha por parte de la elite habría sido una forma de establecer, mantener y reestablecer las relaciones entre los responsables de la administración y el resto de la comunidad. Como se conoce, hasta nuestros días el consumo de la chicha en sus formas tradicionales cumple un función socialmente muy importante, y sin la cual es imposible llevar a efecto cualquier obligación comunal o del ayllu (Allen 1988:137).

Resumiendo, de la información aquí presentada, queda indiscutible que Marayniyoq es un sitio de particular importancia. Por un lado, la presencia de los instrumentos de moler representados en la forma de batanes y moliendas, además de las manos o qollotas, y por otro la ocurrencia de grandes vasijas de cerámica utilizables en el almacenamiento de granos y la fermentación y transportación de bebidas como la chicha, sugieren que el sitio fue un establecimiento edificado por la administración estatal Wari y que como tal funcionó en beneficio de dicha entidad estatal. Las depresiones que presentan los batanes también son indicadores de una actividad no sólo continua, sino también prolongada. En la medida que otros sitios Wari del valle de Ayacucho sean estudiados, se tendrá una mejor visión de la forma como el Estado Wari se organizó en su centro de origen. En efecto, cada esfuerzo orientado al estudio de un sitio Wari provee de información nueva y necesaria para una mejor interpretación de esta importante cultura. Está por demás sostener que una organización como Wari no puede ser estudiada a partir de pocos centros al parecer ocupados por una élite. En definitiva, los especialistas tenemos mucho que aprender acerca de cómo Wari fue organizado en su centro de origen.

\section{Agradecimiento:}

Los trabajos efectuados en Marayniyoq se llevaron adelante con autorización del Instituto Nacional de Cultura (Resolución C/0103-2001) y gracias a un financiamiento otorgado por la Social Sciences and Humanities Research Council de Canadá (SSHRC). Diversas personas e instituciones colaboraron y participaron durante la ejecución del proyecto. Enumerar sería una lista bastante larga y tal vez incompleta, razón por cual extiendo mi profundo agradecimiento a cada una de ellas y cada uno de ellos. Haciendo una excepción, agradezco al Dr. Octavian Catuneanu, del departamento de Tierras y Ciencias Atmosféricas de la Universidad de Alberta, Canadá, por el análisis de las muestras de suelo y roca que condujo. Del mismo modo, mis gracias para el Ingeniero Andrés Portugal Paz, de la facultad de Minas, Geología y Civil de la Universidad de Huamanga (Ayacucho), por la identificación en el campo de las diversas rocas y suelos. Los ingenieros Benjamín Guerrero, del Museo de Antropología, Arqueología e Historia del Perú, y Mauro Gutiérrez, de la Universidad de Huamanga colaboraron con el levantamiento del plano de Marayniyoq. Las figuras 6 y 8 fueron identificadas por Patricia J. Knobloch como Chakipampa 1B y Viñaque, respectivamente. Finalmente, extiendo mi reconocimiento al Dr. Roelf Beukens del Laboratorio de ISOTRACE Accelerator Mass Spectrometry de la Universidad de Toronto, Canadá, por el análisis 
de las muestras de carbón provenientes de Marayniyoq. Este trabajo está basado en dos ponencias presentadas a conferencias efectuadas en Norteamérica y datos obtenidos durante el análisis de las colecciones arqueológicas. Cualquier error o mala interpretación de alguna fuente es responsabilidad mía y no así de las personas o instituciones aquí mencionadas.

\section{Bibliografía}

Adams, J. L.

1999 "Refocusing the role of food-grinding tools as correlates for subsistence strategies in the U.S. Southwest". American Antiquity. 64:475-498.

Allen, C. J.

1988 The Hold Life Has: Coca and Cultural Identity in an Andean Community. Washington, D.C.: Smithsonian Institution Press.

Anders, M. B.

1989 "Wamanga pottery: symbolic resistance and subversion in Middle Horizon epoch 2 ceramics from the planned Wari site of Azángaro (Ayacucho, Peru)", en Cultures in Conflict: Current Archaeological Perspectives (D. C. Tkaczuk \& B.C. Vivian, eds.), pp. 7-18. Chacmool: the archaeological association of the University of Calgary, Calgary.

1991 "Structure and function at the planned site of Azángaro: cautionary notes for the model of Huari as a centralized secular state", en Huari Administrative Structure: Prehistoric Monumental Architecture and State Government (W.H. Isbell \& G.F. McEwan, eds.), pp. 165197. Dumbarton Oaks, Washington, D.C.

Arnold, D.E.

1985 Ceramic Theory and Cultural Process. Cambridge University Press, Cambridge.

1993 Ecology and Ceramic Production in an Andean community. Cambridge University Press, Cambridge.
Arthur, J. W.

2002 Pottery use-alteration as an indicator of socioeconomic status: an ethnoarchaeological study of the Gamo of Ethiopia. Journal of Archaeological Method and Theory 9:331-355.

2003 Brewing beer: status, wealth and ceramic use alteration among the Gamo of South-Western Ethiopia. World Archaeology 34 (3):516-528.

Benavides, $\mathrm{M}$.

1991 Cheqo Wasi, Wari, en Huari Administrative Structure: Prehistoric Monumental Architecture and State Government (W.H. Isbell \& G.F. McEwan, eds.), pp. 55-69. Dumbarton Oaks, Washington, D.C.

Clarke, D. L.

1977 "Spatial information in archaeology", en Spatial Archaeology (D.L. Clarke, ed.), Cobo, B. pp. 1-32. Academic Press, New York.

1956 [1653] Historia del nuevo mundo, en Obras del Padre Bernabé Cobo (Segunda Parte), pp. 5 - 275. Biblioteca de Autores Españoles Tomo XCII. Madrid: Ediciones Atlas.

Cook, A. G.

1987 The Middle Horizon pottery offerings from Conchopata. Nawpa Pacha 22 23:49-90.

David, N.

1998 The Archaeology and Field Archaeology of Grinding at Sukur, Adamawa State, Nigeria. African Archaeological Review 15 (1):13-63.

David, N. \& kramer, k.

2001 Ethnoarchaeology in Action. Cambridge University Press, Cambridge.

D'Altroy, T. N.

2002 The Incas. Blackwell publishing, Malden, Massachusetts.

Flannery, K. V. \& M. Winter

1976 Analyzing household activities, en The Early Mesoamerican Village (K. V. Flannery, ed.), pp.34-46. Academic Press, New York.

Gero, J.

1990 Pottery, power and parties! at Queyash, Peru. Archaeology 43 (2): 52-55. 
Glowacki, M. \& G. F. McEwan

2001 "Pikillacta, Huaro y la gran región del Cuzco: nuevas interpretaciones de la ocupación Wari de la sierra sur”. Boletín de Arqueología PUCP 5:31-49. Pontificia Universidad Católica del Perú, Lima.

Knobloch, P.J.

1991 "Stylistic date of ceramics from the Huari centers", en Huari Administrative Structure: Prehistoric Monumental Architecture and State Government (W.H. Isbell \& G.F. McEwan, eds.), pp. 247258. Dumbarton Oaks, Washington, D.C.

Hastorf, C. A.

1991 "Gender, Space, and Food in Prehistory", en Engendering Archaeology: Women in Prehistory (J. M. Gero \& M. W. Conkey, eds.), pp.: 132-159. Basil, Blackwell, Ltd. Cambridge, Massachusetts.

Isbell, W.H.

2001 "Repensando el Horizonte Medio: el caso de Conchopata, Ayacucho, Perú". Boletín de Arqueología PUCP 4: 9-68. Pontificia Universidad Católica del Perú, Lima.

Isbell, W.H., C. Brewster-Wray \& L. E. Spickard

1991 "Architecture and spatial organization at Huari", en Huari Administrative Structure: Prehistoric Monumental Architecture and State Government (W.H. Isbell \& G.F. McEwan, eds.), pp. 19-53. Washington, D.C.: Dumbarton Oaks.

Isbell, W.H. \& A.COOK

1987 "Ideological origins of an Andean conquest state". Archaeology 40 (4):27-33.

2002 "A New Perspective on Conchopata and the Andean Middle Horizon", en Andean Archaeology II: Art, Landscape, and Society (H. Silverman \& W. H. Isbell, eds.), pp: 249-305. Kluwer Academic \& Plenum Publishers, New York.

Lumbreras, L. G.

1980 "El Imperio Wari", en Historia del Perú, Vol. 2:9-91. Lima: Editorial J. Mejía Baca.

1984 "La unidad arqueológica socialmente significativa (II): la inferencia científica”. Gaceta Arquológica Andina 11:3.
Menzel, D.

1964 "Style and time in Middle Horizon". Nawpa Pacha 2:1-105.

Meyerson, J.

1990 Tambo, Life in an Andean Village. Austin: University of Texas Press.

Moore, J.D.

1989 "Pre-Hispanic beer in coastal Peru: technology and social context of prehistoric production". American Anthropologist 91:682-695.

Morris, C.

1979 "Maize beer in the economics, politics, and religion of the Inca empire", en Fermented Food Beverages in Nutrition (C.F. Gastineau, W.J. Darby \& T.B. Turner, eds.), pp. 21-34. New York: Academic Press.

1988 "A city fit for an Inka”. Archaeology 41 (5): 43-49.

Morris, C. \& D. E. Thompson

1985 Huanuco Pampa: an Inca City and its Hinterland. Thames and Hudson, London.

Murra, J. V.

1983 La organización económica del estado Inca. Siglo XXI \& Instituto de Estudios Peruanos, México \& Lima.

Ochatoma, J. \& M. Cabrera

2001a "Arquitectura y áreas de actividad en Conchopata". Boletín de Arqueología PUCP 4: 449-488. Pontificia Universidad Católica del Perú, Lima.

2001b Poblados rurales Huari: una visión desde Aqo Wayqo Lima: Cono, asociados SAC.

2002 "Religious ideology and military organization in the iconography of a D-shaped ceremonial precinct at Conchopata", en Andean Archaeology II: Art, Landscape, and Society (H. Silverman \& W. H. Isbell, eds.), pp: 225-247. Kluwer Academic \& Plenum Publishers, New York.

Pizarro, P.

1965 [1571] "Relación del descubrimiento de los reinos del Perú”, en Crónicas del Perú $V$, pp. 159-242. Biblioteca de Autores Españoles, Tomo CLXVIII. Ediciones Atlas, Madrid. 
Pozzi-Escot, D.

1985 "Conchopata: un poblado de especialistas durante el Horizonte Medio". Bulletin de l'Institut Français d'Etudes Andines 14 (3-4): 115-129.

1991 Conchopata, a community of potters. En Huari Administrative Structure: Prehistoric Monumental Architecture and State Government (W.H. Isbell \& G.F. McEwan, eds.), pp.81-92. Washington, D.C.: Dumbarton Oaks.

Raymond, J.S.

1992 Highland colonization of the Peruvian Montaña in relation to the political economy of the Huari empire. Journal of the Steward Anthropological Society 20 (12):17-36.

Rowe, J.H.

1946 "Inca Culture at the Time of the Spanish Conquest", en Handbook of South American Indians: The Andean Civilizations, Vol. 2. (J. H. Steward, ed.), pp. 183-330. Smithsonian Institution Bureau of American Ethnology Bulletin 143. Washington, D.C.

Schreiber, K. J.

1991 "The association between roads and polities: evidence for Wari roads in Peru", en Ancient Road Networks and Settlement Hierarchies in the New World (C.D. Trombold, ed.), pp. 243-252. Cambridge: Cambridge University Press.

1992 Wari Imperialism in Middle Horizon Peru. Museum of Anthropology, Anthropological Papers Vol. 87. Ann Arbor: University of Michigan.

Terrell, E. J., J. P. Hart, S. Barut, N. Cellinese, A. Curet, T. Denham, C. M. Kusimba, K. Latinis, R. Oka, J. Palka, M. E. D. Pohl, K. O. Pope, P. R. Williams, H. Haines \& J. E. Staller

2003 "Domesticated landscapes: the subsistence Ecology of plant and animal domestication". Journal of Archaeological Method and Theory 10 (4):323-368.

Valdez, L. M.

1997 "Ecology and ceramic production in an Andean community: a reconsideration of the evidence". Journal of
Anthropological Research 53:65-85.

2002a "Marayniyoq, evidencias de producción de chicha en un establecimiento Wari”. Gaceta Arqueológica Andina 26:69-86.

$2002 \mathrm{~b}$ New archaeological excavations at the wari site of Marayniyoq, Ayacucho, Peru. Ponencia presentada al $21^{\text {st }}$. Annual Northeast Conference on Andean Archaeology and Ethnohistory. Carnegie Museum of Natural History, Pittsburgh, Noviembre 2 3, 2002.

2003 The Grinding stones from the Marayniyoq Wari site in the Ayacucho Valley, Peru". Ponencia presentada al 43 Annual Meeting of the Institute of Andean Studies, University of Berkeley, California, Enero 10-11, 2003.

Valdez, L. M., K. J. Bettcher \& J. E. Valdez

2002 "Investigaciones arqueológicas en Marayniyoq: informe de la segunda temporada”. Boletín del Museo de Arqueología y Antropología 5 (2):31-42. UNMSM, Lima.

Valdez, L. M., J. E. Valdez, K. J. Bettcher \& C. Vivanco

1999 "Excavaciones arqueológicas en el centro Wari de Marayniyoq, Ayacucho". Boletín del Museo de Arqueología y Antropología 2 (9):16-19. UNMSM, Lima.

2001 "Marayniyoq, un establecimiento Wari en el valle de Ayacucho, Perú", en Wari y Tiwanaku: modelos vs. evidencias, Boletín de Arqueología PUC 4: 549. 564. Pontificia Universidad Católica del Perú, Lima.

Williams, R. P. \& J. Isla

2002 "Investigaciones arqueológicas en Cerro Baúl, un enclave Wari en el valle de Moquegua". Gaceta Arqueológica Andina 26:87-120.

Williams, R. P., J. Isla \& D. Nash

2001 "Cerro Baúl: un enclave Wari en interacción con Tiwanaku". Boletín de Arqueología PUCP 5:69-87. Pontificia Universidad Católica del Perú, Lima. 